\title{
Первичные публичные размещения акций: обзор исследований
}

\begin{abstract}
Львутин П.П. ${ }^{32}$, Фетцер О.В. ${ }^{33}$
В данной статье анализируются методы $u$ результать академических исследований IРО. Рассматриваются широко известные и дебатируемье феномень IPO в рамках трех подходов: с точки зрения акционеров, с точки зрения компании как независимой хозяйственной единицы в рамках бизнес- среды и с точки зрения инвестиционного банка и инфраструктуры финансового рынка. Представлен обзор статей по феномену недооченки и переоченки IPO на разных инвестиционных горизонтах, выбора компанией времени для выхода и мотивов выхода на IPO, волнам IPO, эффективности компании после IPO.
\end{abstract}

\section{Введение}

В последнее время с бурным развитием экономик развивающихся стран и становлением их фондовых рынков все больше компаний используют механизм финансирования через продажи акций на публичном рынке - Initial Public Offering (IPO). Наблюдающийся и приближающийся бум IPO делает актуальным исследования в данной области как с практической, так и академической стороны. Проблематика IPO по развитым рынкам исследуется давно, поэтому по данной теме существует целый ряд исследований. В данной статье сделан небольшой обзор работ по данной тематике в западных и международных журналах - в основном по развитым рынкам. В дальнейшем представляется перспективным проведение аналогичных исследований по России и продолжение работы в новых направлениях в рамках тематики IPO.

Проблематику IPO можно рассматривать с трех точек зрения:

- с точки зрения инвесторов (текущих акционеров и новых, покупающих акции на IPO): конфликт интересов, контроль над компанией и размывание, структура собственности при выходе, альтернативные методы финансирования, асимметрия информации, влияние покрытия аналитиками (обзоров аналитиков) департаментов исследований инвестиционных банков на

\footnotetext{
32 Преподаватель кафедры экономики и финансов фирмы ГУ-ВШЭ консультант Ernst \& Young Valuation LLC

33 Студентка 1-го курса магистратуры программы «Стратегическое управление финансами фирмы» ГУ-ВШЭ
} 
результаты IPO, недооценка при выпуске и пониженная доходность $^{34}$ на длинном инвестиционном горизонте;

- c точки зрения компании: влияние IPO на эффективность, рост, конкурентные преимущества, время выхода, площадка для размещения (страна и страна регистрации), влияние на положение компании цены и структуры выпуска;

- с точки зрения инвестиционного банка: методы и технологии выпуска, факторы успешного выхода на IPO, определение структуры выпуска, проблема оценки акций при IPO, стабилизации рынка после начала торгов, влияние репутации андеррайтера на IPO.

Также актуальным направлением в последнее время является анализ вышеперечисленных проблем в разрезе различных стран, сравнение IPO в различных странах с точки зрения их особенностей, а также исследование IPO на развивающихся рынках ввиду их все возрастающего значения и влияние глобализации на процесс IPO (выход на различных площадках).

\section{Исследования IPO с точки зрения инвесторов}

Наиболее освещенной темой исследований в области IPО является блок исследований именно с позиции инвесторов. При этом исследуются три распространенных аномалии при IPO:

- недооценка при размещении (underpricing);

- пониженная доходность от вложений на стадии IPO в долгосрочном периоде (long-term underperformance);

- активизация выхода фирм на IPO в периоды бумов (hot issue markets).

Авторы исследований приводят и тестируют различные взгляды и предположения относительно вышеуказанных аномалий.

Недооценка при размещении ущемляет интересы текущих акционеров, так как они либо продают новым акционерам свои акции по заниженной цене, либо при выпуске новых акций размывают свою долю, и стоимость их акций оказывается ниже после выпуска. Компания также получает меньший объем средств при размещении, что снижает ее ресурсную базу для развития. Понятно, что данная проблема заслуживает внимания.

34 Англ. вариант «underperformance» переводится в данной статье как пониженная доходность и означает, что акции, купленные на IPO, дают доходность ниже, чем сопоставимые уже обращающиеся на рынке акции. Другой широко используемый термин в рамках тематики IPO - «underpricing» - означает размещение акций по заниженной цене, что приводит к росту цены в первый день торгов, и переводится в данной статье как недоценка. 
С другой стороны, отмечен факт пониженной доходности покупаемых при IPO акций по цене закрытия в первый день в долгосрочном периоде, что, естественно, важно для инвесторов, вкладывающихся на длительных инвестиционных горизонтах. Возникают вопросы: почему так происходит и соответственно оправданна ли покупка акции на IPO?

Также вызывают недоумение многочисленные выходы на IPO в периоды бумов рынка, когда котировки по новым IPO кажутся чересчур завышенными.

\section{Феномен недооценки}

Самые известные работы изначально представляют недооценку как следствие асимметрии информации и неопределенности, новые акционеры вознаграждаются пониженной ценой размещения за принятие рисков асимметрии информации и повышенной неопределенности при IPO. Данная логика изложена в работах Рок [Rock, 1986] и Бенвенист и Спинт [Benveniste \& Spindt, 1989].

Исследование Риттер [Ritter, 1991] - одна из первых академических работ, посвященных проблеме недооценки в первые дни выпуска IPO и проблеме пониженной доходности при покупке по цене закрытия первого дня в последующие годы (за 3 года после IPO доходность за период для IPO компаний $34,47 \%$, для невыпускающих акции - 61,86\%). На взгляд автора, данный феномен может объясняться тремя факторами: 1) неправильным риск-менеджментом; 2) случайностью; 3) завышенным оптимизмом инвесторов, в результате чего компании выбирают время, когда инвесторы слишком оптимистично оценивают перспективы компании и размещаются по завышенным ценам.

Раджан и Серваес [Rajan \& Servaes, 1997] задаются вопросом, являются ли три распространенные аномалии IPO неэффективностью рынка, следствием чрезмерной оптимистичности инвесторов или же ограничениями на институциональных инвесторов (невозможностью осуществлять короткие продажи, что выравнивало бы цену на уровне справедливой). Авторы продолжают исследовать аномалии IPO (недооценка, низкая доходность и феномен перегретых рынков), отмеченные в работе Риттер [Ritter, 1991]. Авторы указывают на то, что аналитики, согласно исследованиям, действительно чрезмерно оптимистичны, ссылаясь на работы Абарбанелл [Abarbanell, 1991] и Браун, Фостер и Норин [Brown, Foster, \& Noreen, 1985], Дугар и Натан [Dugar \& Nathan, 1995) и Лин и Макниколс [Lin \& McNichols, 1995]. Мнения аналитиков существенно влияют на рыночную активность, авторы приводят в обоснование исследование Ирвин [Irvine, 1994], показывающее, что объемы торгов значительно возрастают при выпуске инвестиционных отчетов аналитиков. 
Авторы выявляют систематические ошибки в прогнозах аналитиков, что приводит к покупке акций на IPO по завышенным ценам. Тем не менее не ясно, является это результатом того, что инвесторы следуют рекомендациям аналитиков, или аналитики следуют настрою рынков (причинность не ясна).

Авторы также выявляют, что при оптимистичном прогнозе аналитиков по только что вышедшим на IPO компаниям еще большее количество компаний выходят на IPO. При большем росте компании нуждаются в большем финансировании и выходят на рынок. Кроме того, повышенный оптимизм аналитиков перегревает рынки, чем пользуются фирмы, выпуская акции по завышенным ценам.

Более того, компании с повышенными прогнозами роста не дают доходности даже на уровне рынка (индексов). Авторы приводят также ссылку на работы Лафран и Риттер [Loughran \& Ritter, 1995] и Раджан и Серваес [Rajan \& Servaes, 1995], документирующие низкую отдачу по акциям IPO в последующие годы: 5-7\% на протяжении 5 лет после IPO. Данный факт, по мнению авторов, объясняется выходом компании на рынки с выпусками акций в периоды чрезмерных ожиданий инвесторов и соответственно высоких значений мультипликаторов (P/E) по историческим меркам.

Вопрос размещений по завышенным оценкам, согласно авторам, также рассматривается в работах Лернер [Lerner, 1994], Джэйн и Кини [Jain \& Kini, 1994] и Миккельсон и Ша [Mikkelson \& Shah, 1994].

Тэо, Вонг и Рао [Teoh, Wong, \& Rao, 1995] добавляют манипуляции фирм в расчетах своих прибылей для получения лучшей цены при размещении как фактор, объясняющий низкую последующую доходность.

В заключение авторы предлагают идеи по возможному исследованию причинности связи: или инвесторы следуют прогнозам аналитиков, или же аналитики отражают ожидания инвесторов. При более уверенном исследовании можно будет использовать прогнозы аналитиков для оценки ожиданий рынка.

Аггарвал, Прабхала и Пури [Aggarwal, Prabhala \& Puri, 2002] рассматривают феномен недооценки, отталкиваясь от работы Лафран, Риттер и Ридквист [Loughran, Ritter, \& Rydqvist, 1994], в которой документируется факт высокой средней доходности в первый день торгов после IPO (19,25\%). Авторы подтверждают теорию букбилдинга, согласно которой, институциональным инвестором аллокируется большая доля в IPO при высоком спросе на акции.

Авторы обращают внимание на поведение андеррайтеров, распределяющих большую долю IPО с повышенным спросом в пользу институциональных инвесторов, ссылаясь на свидетельства в работах Пулиам и Смит [Pulliam \& Smith, 2000], Пулиам, Смит и Гаспарино [Pulliam, Smith, \& Gasparino, 2000] и Смит и Пулиам [Smith \& Pulliam, $2000,2001]$. Объяснение авторы находят во взаимной неформальной 
договоренности с институциональными клиентами о направлении заявок о сделках в дальнейшем через брокеров андеррайтера. Также авторы упоминают работу Гаспарино, Шредер и Кранхолд [Gasparino, Schroeder, \& Kranhold, 2000], затрагивающих вопросы аллокации при IPO и предлагающих улучшить регулирование в данной области. По мнению авторов, распределение IPO в пользу институциональных инвесторов может объясняться также и ответной реакцией на предоставление информации о спросе на акции со стороны институциональных инвесторов андеррайтеру. В своей работе авторы оценивают данные вопросы эмпирически.

Проблема в исследовании данной области процесса IPO состоит в том, что не раскрываются данные по аллокации акций при IPO. Авторам удалось получить данные по распределению акций в IPO институциональным и розничным покупателям. Эмпирика такова, что $\begin{array}{llllll}\text { около } 3 / 4 & \text { акций (взята медиана по всем } & \text { IPO) аллокируется }\end{array}$ институциональным инвесторам.

Авторы также упоминают работы с теорией бук-билдинга ${ }^{35}$ Бенвенисте и Спинт [Benveniste \& Spindt, 1989], Корнели и Голдрич [Cornelli \& Goldreich, 2001], и Максимович и Пичлер [Maksimovic \& Pichler, 2001], которая заключается в том, что в процессе бук-билдинга институциональные инвесторы предоставляют информацию андеррайтеру о текущем спросе на акции, что дает возможность андеррайтеру лучше определить оптимальный диапазон цены размещения и получить цену при размещении в верхней части диапазона. Акции с ценой размещения в верхней части диапазона, согласно исследованию авторов, имеют больший рост сразу после IPO. Соответственно андеррайтеры в обмен на это аллокируют институциональным инвесторам большую долю IPO с хорошими перспективами. Также институциональные инвесторы в дальнейшем предоставляют возможность андеррайтеру получать комиссии от его брокерского бизнеса, осуществляя через него покупки и продажи акций.

Но участие институтов в недооцененных IPO выше, чем предсказывает модель бук-билдинга. Авторы оценивают и подтверждают теорию Рок [Rock, 1986] об обладании институтами частной (инсайдерской) информацией.

Клифф и Дениз [Cliff \& Denis, 2004] предлагают гипотезу недооценки акций в момент IPO, заключающуюся в том, что акции продаются по заниженным ценам как компенсация высококачественному андеррайтеру за качественное аналитическое покрытие после IPO. Авторы строят модели зависимости недооценки от качества андеррайтера и присутствия высококлассных аналитиков в команде, покрывающей IPO.

35 Бук-билдинг - изучение спроса на акции через общение с потенциальными инвесторами и составление книги заявок на покупку акций при IPO. 
Данные результаты робастны к прочим экзогенным детерминантам недооценки, а также эндогенности недооценки. Также авторы оценивают, что вероятность переключения к другому андеррайтеру при последующих выпусках акций отрицательно зависит от неожиданно высокого покрытия аналитиками, что подтверждает изначальную гипотезу.

В случае, если андеррайтер не дает адекватное ожиданиям фирмы качество покрытия, вероятность смены андеррайтера при следующем выпуске повышается.

Авторы подвергают сомнению гипотезу недооценки по стратегическим мотивам Аггарвал и пр. [Aggarwal et al., 2002], заключающуюся в том, что акции распродаются по заниженным ценам для лучшего и более широкого распределения и положительной динамики в последующем. Согласно данной теории, неясно, почему существует положительная связь между качеством покрытия аналитиками и величиной недооценки.

Исследование авторов также позволяет объяснить наблюдения Битти и Уэлч [Beatty \& Welch, 1996] того, что зависимость величины недооценки от престижа андеррайтера сменила знак с отрицательного в 1970-1980-х на положительный в 1990-е. С позиции авторов это объясняется тем, что престижные андеррайтеры предоставляют лучшее покрытие, поэтому фирмы вознаграждают их повышенной недооценкой. Данный факт согласуется также с тенденцией роста пакетов компенсаций аналитиков.

Картер, Дарк и Сингх [Carter, Dark, \& Singh, 1998] показывают, что недостаток в долгосрочной доходности IPO компаний за 3 года после IPO по сравнению с рынком не настолько велик для компаний, размещаемых престижными андеррайтерами. Также престижные андеррайтеры получают меньшую недооценку. Картер и Манастер используют специальную метрику для измерения престижа андеррайтера. В работе производится обновленная оценка данной метрики и оценивается, что она очень значима для объяснения недооценки и долгосрочной доходности IPO. Авторы также исследуют и другие показатели престижа андеррайтера, предложенные Джонсон и Миллер [Johnson \& Miller, 1988] и Меггинсон и Вайс [Megginson \& Weiss, 1991]. Согласно анализу авторов, метрика Carter-Manaster (CM) наиболее значима в моделях оценки влияния престижа андеррайтера на величину недооценки и долгосрочную низкую доходность IPO. В работе приводится список инвестиционных банков с соответствующим рангом по метрике СМ для учета переменной престижа андеррайтера в моделях анализа IPO.

Картер и Манастер [Carter \& Manaster, 1990] предлагают и тестируют следующую модель. Авторы отталкиваются от работы Рок [Rock, 1986], утверждающей, что акции выпуска IPO более рискованны, следовательно, инвесторы в IPO будут требовать большую доходность 
(заниженные цены). Менее рисковые фирмы могут устранить асимметрию информации, используя престижных андеррайтеров.

Авторами предлагается метрика, оценивающая престиж андеррайтера, а также определяется отрицательная связь между престижем андеррайтера и величиной начальной доходности IPO.

\section{Феномен пониженной доходности}

Горячо обсуждаемая проблема пониженной доходности по акциям компаний, вышедшим на IPO, состоящая в том, что акции компании после первичного публичного размещения не оправдывают ожиданий и приносят доходность ниже, чем средства, вложенные в непубличные компании такого же размера, рассматривается в работе Лафран и Риттер [Loughran \& Ritter, 1995]. Авторы приводят результаты анализа 5-летней доходности акций компаний, проводивших IPO с 1970-го по 1990-й годы. Несмотря на рост в последующие 6 месяцев после IPO, акции данных компаний давали доходность намного ниже, чем аналогичные компании по риску, размеру и потенциалам роста, но не выпускавшие акции на бирже. Авторы проводят корректировки на размер, отрасль и потенциал pocта (Market-to-Book effect) и показывают, что проблема низкой доходности после публичного размещения характерна не только для первичного публичного размещения - IPO, но и для последующих размещений акций — SEO (Seasonal Equity Offering).

Так, средние пятилетние доходности компаний, выходивших на IPO, составляют только 5\%, в то время как для аналогичных компаний, не размещавших акции, доходность составляет $12 \%$ в год. Для SEO соответствующие цифры составляют 7 и 12\% в год. При этом проблема пониженной доходности возникает после первых 6 месяцев с момента выпуска, а становится особенно острой в последующие 18 месяцев. В результате для получения равного богатства через 5 лет после IPO инвесторы должны вложить на 44\% больше в акции компаний IPO, чем в акции не выходящих на IPO компаний. Через 5 лет после размещения разница между компаниями, выходившими на IPO или SEO и не выходившими, практически нивелируется.

Авторы используют три методики анализа. Во-первых, t-статистику относительной доходности за период для компаний, выпускающих и не выпускающих акции. Вторая методика заключается в построении панельных регрессий по месячным доходностям для каждой акции. Третья методика считает t-статистики трехфакторных временных рядов доходности портфелей акций компаний, выпускающих и не выпускающих акции на бирже. Пробовались возможные вариации исследования данных - по используемым весам, по временным интервалам, объединение компаний по группам, но результаты оставались устойчивыми. 
Авторы опровергают в своем исследовании одно из возможных объяснений, заключающееся в долгосрочной корректировке доходностей (long-term return reversals), так как IPO происходят после периодов высоких доходностей.

В добавление к этому авторы оценивают, что беты компаний, выпускающих акции на бирже, выше, чем беты невыпускающих фирм, что соответственно должно приводить к большей премии за риск и доходности по акциям компаний, выходящих на биржу.

В работе предлагаются следующие объяснения загадки низкой доходности IPO и SEO:

1. Многие маленькие компании в первые годы своей деятельности растут высокими темпами, и инвесторы ошибочно переоценивают будущие потоки компании.

На взгляд авторов, компании используют моменты (windows of opportunities), когда их акции переоценены, для выхода на биржу и продажи акций по завышенной цене. Операционная доходность компаний резко возрастает и очень высока; как правило, в такие периоды и инвесторы ожидают дальнейшего роста. Переоценка возможностей роста инвесторами и приводит к завышенной оценке акций. Для быстрорастущих компаний убеждение инвесторов в бурном росте дается еще легче. Авторы подкрепляют свои свидетельства исследованиями Джэйн и Кини [Jain \& Kini, 1994], Миккельсон и Ша [Mikkelson \& Shah, 1994] и Лернер [Lerner, 1994], которые приходят к аналогичным выводам: операционные денежные потоки на активы снижаются после IPO, несмотря на рост продаж.

Главное объяснение авторов, как мы считаем, состоит в том, что инвесторы делают ставку на долгосрочные ожидания роста. Так как удостовериться в их корректности и переоценить свой опыт возможно только через длительное время, то потребуется очень долгий период для переоценки и корректировки оценок акций. В результате из-за высокой оптимистичности инвесторы систематически ошибаются.

2. Возможное объяснения для случая с SEO может заключаться в том, что компании размещают акции в периоды, когда рынок переоценивает компанию, а после размещения инвесторы не делают корректировку оценки акций.

Рынок, несмотря на падение акций после объявления о дополнительном выпуске, согласно гипотезе асимметрии информации, попрежнему неправильно оценивает акции. Падение происходит всего лишь на несколько процентов, в то время как по подсчету Лафран и Риттер [Loughran \& Ritter, 1995] требуется снижение на 33\% и более. Для проверки гипотезы асимметрии информации Ли [Lee, 1994] провел исследование, где ввел в анализ продажи инсайдерами. Тем не менее оказалось, что и инсайдеры склонны к неправильной оценке акций. 
В итоге ни эффект M-to-B, ни размер, ни асимметричная информация полностью не объясняют феномен пониженной доходности акций выпускающих компаний.

Феномен пониженной доходности характерен не только для США, авторы ссылаются на работы Левис [Levis, 1993a, 1993b], Марш [Marsh, 1979] и Лафран, Риттер и Ридквист [Loughran, Ritter \& Ridqvist, 1994], подтверждающие пониженную доходность по акциям компаний IPO в Великобритании и других странах в 1962-1972 гг.

Иккенберри, Лаконишок и Вермален [Ikenberry, Lakonishok \& Vermaelen, 1994] документируют более высокую доходность по акциям компаний, выкупающих свои акции.

Гомперс и Лернер [Gompers \& Lerner, 2003] отталкиваются от работы и опровергают эмпирические результаты Риттер [Ritter, 1991] и Лафран и Риттер [Loughran \& Ritter, 1995] о низкой доходности IPO в долгосрочном периоде. Основным опровергающим аргументом явился подход к исчислению доходности. В случае оценки доходности методом определения доходностей по временным отрезкам (event-time buy-and-hold return) действительно получается доходность ниже бенчмарков ${ }^{36}$. Однако при оценке кумулятивной избыточной доходности (cumulative abnormal returns) получается, что никакой пониженной доходности не наблюдается. Данный факт легко понять на примере средней арифметической доходности и средней геометрической. Средняя арифметическая может быть положительной, при этом средняя геометрическая остается на том же уровне. Если акция выросла со 100 до 150, на 50\%, а затем упала на 40\%, до 90, то средняя арифметическая доходность будет положительная: $+5 \%$ $=(50 \%-40 \%) / 2$; в то же время фактически акция снизилась со 100 до 90 за два периода, что равносильно средней геометрической около $-5 \%$. По расчетам авторов, на длительном горизонте IPO дают доходность на уровне рыночной.

Также авторы оценивают регрессии САРМ и Фама - Френча и находят, что свободный коэффициент незначим, что говорит об отсутствии систематического превышения доходности IPO доходности рынка.

\section{Сигнальные эффекты при IРО}

Множество исследований посвящено анализу зависимости между стоимостью компании и долей, сохраненной собственниками.

Риттер [Ritter, 1984] вслед за Доунс и Хайдель [Dawnes \& Heidel, 1982] проводит эмпирическую проверку гипотезы сигнальных эффектов (signaling hypothesis), предложенной Лиланд и Пайль [Leland \& Pyle, 1977].

36 Бенчмарк (benchmark) - базовый показатель, относительно которого проводится сравнение (доходности, мультипликатора и других характеристик). 
Суть ее состоит в том, что стоимость компании при первичном публичном размещении должна положительно зависеть от доли компании, которую оставляют себе первоначальные собственники. Из модели Лиланд и Пайль [Leland \& Pyle, 1977] прямо следует, что рыночная стоимость компании должна положительно зависеть от суммы полученного во время IPO капитала и доли, сохраненной первоначальным собственником.

Вторым возможным объяснением существования корреляции между сохраненной долей и рыночной стоимостью компании является гипотеза «эффекта богатства»: чем выше рыночная стоимость компании, тем меньшую долю необходимо продать собственникам для привлечения определенного объема капитала.

Третий подход к объяснению взаимосвязи сохраненной доли и рыночной стоимости компании - агентская теория - предполагает, что увеличение доли продаваемого инсайдерами капитала приводит к усилению оппортунистического поведения менеджеров, что негативно сказывается на стоимости компании.

Для эмпирической проверки гипотез используется выборка из 559 фирм, разместившихся в период 1965-1973 годов с ежегодными продажами выше \$1 млн, бухгалтерской стоимостью более $\$ 0,5$ млн и положительной прибылью в 1980 году. Для определения зависимости рыночной стоимости от доли компании, сохраненной первоначальными собственниками, оцениваются регрессии:

(1) market $=\beta_{0}+\beta_{1} \times$ alpha $+\beta_{2} \times$ earnings $+\beta_{3} \times$ investment $+\varepsilon$,

$$
\text { alpha }=\gamma_{0}+\gamma_{1} \times \text { market }+\gamma_{2} \times \text { earnings }+\gamma_{3} \times \log _{\text {_ sales_growth_rate }+\eta,},
$$

где $\alpha$ - доля сохраненного первоначальными собственниками капитала, earnings - доходы компании до выхода на биржу, investment средства, привлеченные в ходе IPO.

Уравнения оцениваются взвешенным и двухшаговым МНК. Тестирование зависимости между стоимостью компании и долей, сохраненной собственниками, показывает, что агентская теория наиболее верно отражает взаимосвязь. Автору, однако, не удается полностью подтвердить гипотезу сигнальных эффектов и эффект богатства, так что вопрос об их адекватности остается для автора открытым.

Гэйл и Стиглиц [Gale \& Stiglitz, 1989] ссылаются на работу Лиланд и Пайль [Leland \& Pyle, 1977] и Стиглиц [Stiglitz, 1982], в которых рассматривается сигнальный эффект новым инвесторам на стадии IPO о качестве фирмы через удержание доли изначальным владельцем. При продаже бизнеса с неблагоприятными перспективами владелец пожелает избавиться от как можно большей доли. Напротив, при хороших перспективах владелец удерживает большую долю, что передает информацию новым покупающим акционерам и расценивается ими положительно. 
Тем не менее владельцы фирм с негативными перспективами осознают это и могут имитировать поведение хороших фирм. Авторы строят теоретическую модель, где рассматривается возможность продажи акций изначальными владельцами впоследствии, после начала торгов. В данном случае изначальный владелец подвергается большему риску, так как цена акции может пойти вниз (шок спроса).

Авторы строят модель на основе следующих переменных. Стоимость фирмы равна $\mathrm{s}$, изначальный акционер знает истинную стоимость $\mathrm{s}_{\mathrm{H}}-$ для хороших фирм, $\mathrm{s}_{\mathrm{L}}$ - для фирм с низким потенциалом. Переменные $\mathrm{z}_{1}$ и $\mathrm{z}_{2}$ представляют шоки рынка: цена акции может меняться под воздействием внешних по отношению к фирме факторов (market sentiment, etc.).

(3) $\widetilde{V}=\widetilde{s}+\widetilde{z}_{1}+\widetilde{z}_{2}$

(4) $s_{H}>s_{L}>K$

(5) $\widetilde{W}=W_{0}-\widetilde{K}+\widetilde{R}$

(6) $\widetilde{R}=p_{1} q_{1}+p_{2} q_{2}-\widetilde{V}\left(1-q_{1}-q_{2}\right)$

$\mathrm{K}$ - необходимая сумма вложений, $\mathrm{W}$ - благосостояние изначального акционера, $\mathrm{R}$ - доходность для изначального акционера.

$\mathrm{p}_{1}$ и $\mathrm{p}_{2}$ - цены продажи акций в периоды 1 и 2 соответственно,

$\mathrm{q}_{1}$ и $\mathrm{q}_{2}$ - доли, продаваемые изначальным акционером в периоды 1 и 2 соответственно.

Функция ожидаемой полезности несклонного к риску агента:

(7) $E U(\widetilde{R})=E U\left(\widetilde{W}-W_{0}+K\right)$

Авторами строятся модели с объединяющими и разделяющими равновесиями. Основной результат состоит в том, что при незначительно различающихся издержках ожидания и продажи в последующие периоды, a также при низкой степени неопределенности будет существовать объединяющее равновесие и невозможно будет разделить фирмы на качественные и некачественные по посылаемому сигналу, т.е. сигнал неэффективен. Авторы предлагают использовать модель для анализа многопериодного сигнального эффекта через последующие инсайдерские продажи.

Работа представляется интересной с точки зрения применения техники теоретического моделирования феномена асимметрии информации и сигнальных эффектов для понимания факторов, релевантных при IPO и влияющих на асимметрию информации, ее важность и возможность устранения. Сигнальным эффектом в модели является доля продажи изначальных владельцев и величина недооценки при размещении (underpricing): согласно взгляду авторов, владельцы фирмы с благоприятными перспективами могут позволить себе продать акции по заниженной цене, так как существует потенциал роста их благосостояния. 


\section{Эффект структуры капитала при IРО}

В работе Филд, Касарэс [Field, Laura Casares, 1996] отмечается повышенная доходность акций IPO компаний в последующие годы после IPO для ситуации с большим участием в капитале институциональных инвесторов при IPO. Однако, на наш взгляд, данная проблема имеет более широкие рамки для анализа, так как на более длительном периоде включается в действие мониторинговая (контролирующая) роль институциональных инвесторов, а также возникает вопрос причинности, участвуют ли институты в хороших компаниях или компании хорошо работают вследствие участия и мониторинга институтов.

Брав и Гомперс [Brav \& Gompers, 1997] сравнивают низкую долгосрочную доходность компаний, выходящих на IPO, которые поддерживаются венчурными фондами и выходят самостоятельно, без поддержки последних.

По оценке авторов, компании с поддержкой со стороны венчурных фондов дают доходность немного ниже некоторых бенчмарков и доходности, предсказываемой моделью Фама и Френча [Fama \& French, 1993]. В то же время IPO небольших и независимых от венчурных фондов компаний дают долгосрочную доходность значительно ниже. Авторы приходят к заключению, что низкая долгосрочная доходность компаний скорее феномен низкой долгосрочной доходности отдельных типов компаний, нежели компаний, выходящих на IPO.

Сводная информация по основным исследованиям в области анализа IPO с точки зрения старых и новых акционеров представлена в таблице 1. 
Таблица 1.

Основные исследования тематики IРО с точки зрения инвесторов

Таблица 2. Основные исследования тематики IPO с точки зрения инвесторов

\begin{tabular}{|c|c|c|c|}
\hline Авторы и год & Основные проблемы & Метод исследования & Основные результаты \\
\hline Jay Ritter, 1984 & $\begin{array}{l}\text { Исследование связи стоимости } \\
\text { компании и сохраненной доли } \\
\text { первоначальных собственников } \\
\text { после ІРО. Тестирование } \\
\text { гипотез сигнальных эффектов, } \\
\text { «эффекта богатства» и } \\
\text { агентской теории. }\end{array}$ & $\begin{array}{l}\text { Эмпирическая проверка гипотез. } \\
\text { Построение регрессии для: 1) } \\
\text { рыночной стоимости компании в } \\
\text { зависимости от доли прежних } \\
\text { собственников, доходов и } \\
\text { инвестиций и 2) доля компании, } \\
\text { которую сохраняют прежние } \\
\text { собственники в зависимости от } \\
\text { рыночной стоимости, доходов и } \\
\text { роста продаж. Оценка методом } \\
\text { взвешенного и двухшагового } \\
\text { МНК. }\end{array}$ & $\begin{array}{l}\text { Агентская теория наиболее верно отражает } \\
\text { взаимосвязь. Автору не удается полностью } \\
\text { подтвердить гипотезу сигнальных эффектов и } \\
\text { эффекта богатства. }\end{array}$ \\
\hline $\begin{array}{l}\text { Ian Gale \& Joseph } \\
\text { E. Stiglitz, } 1989\end{array}$ & $\begin{array}{l}\text { Асимметрия информации при } \\
\text { выходе на ІРО, механизм } \\
\text { сигнальных эффектов качества } \\
\text { фирмы через долю, } \\
\text { сохраняемую начальным } \\
\text { акционером, и величину } \\
\text { недооценки. Исследуется } \\
\text { вопрос инсайдерской торговли }\end{array}$ & $\begin{array}{l}\text { Теоретическая модель. Основные } \\
\text { переменные: стоимость фирмы; } \\
\text { шоки рынка; доли, продаваемые } \\
\text { изначальным акционером. } \\
\text { Вероятности раскрытия } \\
\text { информации о качестве фирмы в } \\
\text { последующие периоды, степень } \\
\text { неопределенности и рыночый }\end{array}$ & $\begin{array}{l}\text { Объединяющее равновесие доминирует } \\
\text { разделяющее, так что обоим типам акционеров } \\
\text { выгоднее продавать большую часть сразу при } \\
\text { выпуске IPO, возможность сигнальных эффектов } \\
\text { ограничена. Ждать и продавать позднее приносит } \\
\text { большие издержки обоим типам акционеров. } \\
\text { Сигнальные эффекты срабатывают лишь в случаях } \\
\text { со значительно различающимися затратами }\end{array}$ \\
\hline
\end{tabular}

Выпуск \#1, 2007 


\begin{tabular}{|c|c|c|c|}
\hline & после выпуска. & сентимент. & $\begin{array}{l}\text { ожидания и дальнейшей продажи. Возможно } \\
\text { моделирование многопериодных сигнальных } \\
\text { эффектов через инсайдерские продажи. }\end{array}$ \\
\hline $\begin{array}{l}\text { Richard Carter \& } \\
\text { Steven Manaster, } \\
1990\end{array}$ & $\begin{array}{l}\text { Влияние престижа } \\
\text { андеррайтера на величину } \\
\text { недооценки и долгосрочную } \\
\text { доходность IPО, гипотеза } \\
\text { устранения асимметрии } \\
\text { информации и сигнальных } \\
\text { эффектов рынку через престиж } \\
\text { андеррайтера. }\end{array}$ & $\begin{array}{l}\text { Оценка престижа андеррайтера с } \\
\text { использованием метрики СМ } \\
\text { (Carter-Manaster). }\end{array}$ & $\begin{array}{l}\text { В целом подтверждается гипотеза Рок [Rock, 1986] } \\
\text { асимметрии информации при IPO. Найдена } \\
\text { отрицательная связь между престижем } \\
\text { андеррайтера и величиной начальной доходности } \\
\text { IPO (day one return, or IPO price run-up), что } \\
\text { подтверждает гипотезу авторов относительно } \\
\text { сигнальных эффектов. }\end{array}$ \\
\hline $\begin{array}{l}\text { Tim Loughran, } \\
\text { Jay Ritter, } 1995\end{array}$ & $\begin{array}{l}\text { Исследование проблемы } \\
\text { пониженной доходности после } \\
\text { IPO и SEO. }\end{array}$ & $\begin{array}{l}\text { Анализ доходностей акций после } \\
\text { IPО в течении } 5 \text { лет: анализ } \\
\text { средних показателей доходностей } \\
\text { для компаний, выходивших и не } \\
\text { выходивших на IPO. Построение } \\
\text { регрессий и временных рядов для } \\
\text { объяснения феномена низкой } \\
\text { отдачи. Выявление эффекта } \\
\text { низкого Market-to-Book. }\end{array}$ & $\begin{array}{l}\text { Доходность акций компаний, выходивших на IPO, } \\
\text { составляет только 5\%, в то время как для } \\
\text { аналогичных компаний, не размещавших акции, } \\
\text { доходность составляет 12\% в год. } \\
\text { У компаний с более низким коэффициентом } \\
\text { Мarket-to-Вoоk доходность акций меньше. Но } \\
\text { эффект низкого коэффициента Market-to-Book } \\
\text { лишь частично объясняет феномен пониженной } \\
\text { доходности. } \\
\text { Для дальнейшего тестирования: маленькие } \\
\text { компании в первые годы растут высокими темпами } \\
\text { и инвесторы переоценивают будущие потоки }\end{array}$ \\
\hline
\end{tabular}




\begin{tabular}{|c|c|c|c|}
\hline & & & компании. \\
\hline \multirow{15}{*}{$\begin{array}{l}\text { Raghuram Rajan } \\
\& \text { Henri Servaes, } \\
1997\end{array}$} & Влияние покрытия аналитиков & Оценка различий в доходности в & 1. Более недооцененные выпуски характеризуются \\
\hline & на феномен недооценки, & первые дни сразу после выпуска и & большим покрытием аналитиков, при этом \\
\hline & низкой отдачи и «горячих» & долгосрочной доходности & аналитики завышают прогнозы роста акций в \\
\hline & рынков: & компаний разных персентилей, & среднем на 5\%, и ошибка прогноза выше в более \\
\hline & 1) влияет ли покрытие & разбитых по критерию покрытия & длительном периоде. \\
\hline & аналитиков на недооценку IPO; & аналитиками и оптимистичности & 2. Прогнозы высокого роста по компаниям отрасли \\
\hline & 2) существуют ли & прогнозов аналитиков по & приводят к повышению числа IPO в отрасли. \\
\hline & систематические ошибки в & компании. & 3. Компании IPO, по которым прогнозируется \\
\hline & прогнозах аналитиков по & & наибольший рост, не превосходят доходность \\
\hline & компаниям, выходящим на IPO; & & рынка (индексов); разница между компаниями двух \\
\hline & 3) связано ли количество IPO с & & крайних персентилей по прогнозируемому росту — \\
\hline & оптимизмом аналитиков; & & выше $100 \%$. \\
\hline & 4) как влияет оптимизм & & 4. Компании дают тем меньшую отдачу на \\
\hline & аналитиков на долгосрочную & & длительном горизонте, чем выше прогнозы роста от \\
\hline & отдачу вложений в IPO. & & аналитиков. \\
\hline \multirow{8}{*}{$\begin{array}{l}\text { Alon Brav \& Paul } \\
\text { A. Gompers, } 1997\end{array}$} & Влияние участия венчурных & Сравнение доходностей компаний & Низкая долгосрочная доходность — скорее \\
\hline & фондов и институциональных & разных групп (поддерживаемых & феномен отдельных типов компаний, а не IPO \\
\hline & инвесторов в выводе компаний & венчурными фондами и не & компаний. Компании с поддержкой со стороны \\
\hline & на IPО и долгосрочную & поддерживаемых, малых и & фондов дают доходность, не намного ниже \\
\hline & доходность IPO. & крупных, недо- и переоцененных) & бенчмарков. Небольшие компании дают \\
\hline & & между собой, с бенчмарками и & действительно низкую долгосрочную доходность, \\
\hline & & ожидаемой доходностью по & но институциональные инвесторы в них, как \\
\hline & & модели Фама и Френча. & правило, не участвуют. Низкая доходность малых \\
\hline
\end{tabular}


Richard B. Carter, Влияние престижа

Frederick H. Dark, андеррайтера на величину

and Ajai K. Singh, недооценки и долгосрочную

1998

доходность IPO.

Reena Aggarwal,

Nagpurnanand R.

Prabhala \& Manju

Puri, 2002

\section{Влияние участия}

институциональных

инвесторов на недооценку в

IPO, тестирование теории бук-

билдинга недооценки. Вопрос

и возможные объяснения

распределения недооцененных

IPO между

институциональными и

частными инвесторами в IPO, а

также роль андеррайтеров в

данном процессе.
Оценка престижа андеррайтера с

использованием различных метрик

\section{Оценка доли акций,}

аллокированных при IPO

институтам, при цене в нижней и

верхней области диапазона цены

размещения с соответственно

меньшими и большими

перспективами роста после

размещения. Оценка выборки

размещений девяти андеррайтеров

по двухуровневой оценке. Авторы

корректируют оценки на

эндогенность участия институтов в

IPO.

компаний может влиять на доступность капитала

данным фирмам, поэтому важно изучить данную аномалию.

Наилучшей метрикой является предложенная

Carter-Manaster (CM), она значимо объясняет недооценку и долгосрочную доходность IPO. В работе приведен список андеррайтеров с рейтингом их престижа, что может быть использовано для учета данной переменной в моделях анализа IPO. Институциональные инвесторы в большей степени, чем частные инвесторы, участвуют в недооцененных IPO. Подтверждается теория букбилдинга (андеррайтер дает преференции институциональным инвесторам, так как они предоставляют рыночную информацию о спросе на акции и дают брокерский бизнес), но институциональные инвесторы участвуют в большей степени в недооцененных IPO (underpriced), что объясняется теорией букбилдинга. Объясняется это частной закрытой информацией, которой обладают институциональные инвесторы или андеррайтеры, что позволяет им не покупать лимоны (lemons). 


\begin{tabular}{|c|c|c|c|}
\hline \multirow{5}{*}{$\begin{array}{l}\text { \& Josh Lerner, } \\
2003\end{array}$} & & (abnormal) кумулятивной & т.е. ожидаемой рынком (no underperformance), \\
\hline & & доходности для акций IPO, & также не дают и сверхдоходности (свободный \\
\hline & & построение регрессий САРМ, & коэффициент в регрессиях САРМ и Фама - \\
\hline & & Фама - Френча. Период 1935- & Френча почти нулевой и незначим). \\
\hline & & 1972 годы. & \\
\hline \multirow{5}{*}{$\begin{array}{l}\text { Michael T. Cliff \& } \\
\text { David J. Denis, } \\
2004\end{array}$} & \multirow{5}{*}{$\begin{array}{l}\text { Влияние покрытия аналитиков } \\
\text { на размер недооценки при IPO. }\end{array}$} & Построение моделей зависимости & Существует положительная связь между наличием \\
\hline & & недооценки от наличия & высококлассного аналитика в команде покрытия и \\
\hline & & высококлассных аналитиков в & недооценкой, что может говорить о \\
\hline & & команде покрытия & вознаграждении андеррайтеру за качественное \\
\hline & & & покрытие в виде повышенной недооценки. \\
\hline
\end{tabular}




\section{Исследования IPO с точки зрения компании}

С выходом на публичный рынок компания получает определенные преимущества, но IPO не является абсолютно безупречным с точки зрения влияния на компанию и ее акционеров как при выпуске, так и впоследствии. IPO связано с различными затратами и недостатками для компании. При выходе компания должна производить существенные изменения в своей структуре и процессах деятельности, возникает масса проблем корпоративного управления, что приводит к возникновению дополнительных неэффективностей при публичной собственности. Опять же недооценка влияет на объем средств, которые привлекает компания, а также может определяться действиями и мотивациями менеджеров. В данном разделе сделан обзор исследований по обозначенному комплексу проблем.

Аруаслан, Кук и Кишник [Arugaslan, Cook, \& Kieschnick, 2004] опровергают исследование Брэннан и Франкс [Brennan \& Franks, 1997] и Стафтон и Цехнер [Stoughton \& Zechner, 1998], выдвигающее гипотезу, что соображения по поводу мониторинга могут создавать стимулы менеджерам размещать акции по заниженным ценам. Согласно авторам наблюдения по детерминантам, определяющим начальную доходность IPO, участие институциональных инвесторов и вероятность поглощения после IPO не согласуются с аргументацией Брэннан и Франкс [Brennan \& Franks, 1997] и Стафтон и Цехнер [Stoughton \& Zechner, 1998]. Гипотеза пониженного мониторинга Брэннан и Франкс [Brennan \& Franks, 1997], заключающаяся в том, что при заниженной цене менеджеры привлекают внимание большего числа инвесторов и соответственно могут распределить выпуск между большим числом инвесторов, каждому небольшую долю. Такая распыленная собственность понижает возможности последующего контроля и смещения менеджмента в случае низкой эффективности.

Стафтон и Цехнер [Stoughton \& Zechner, 1998], напротив, предлагают следующую идею: менеджеры стремятся максимизировать стоимость, а стоимость выше при большем участии институциональных инвесторов в капитале фирмы. При ограничении числа акций, аллокируемых мелким частным инвесторам, и появляется недооценка. Это гипотеза повышенного мониторинга. Согласно данной логике, доля институциональных инвесторов после IPO выше для фирм с большей недооценкой.

Авторы приходят к выводу, что размещения двойного класса IPO занижаются меньше, чем IPO одного класса, так как они значительно больше по объему. Участие институциональных инвесторов в IPO определяется размером компании, а не статусом (один или два класса) IPO или недооценкой. Размер фирмы и пакет институциональных инвесторов, 
а не статус IPO или величина недооценки, определяют вероятность поглощения в последующие 3 года после размещения.

В статье Джэйн и Кини [Jain \& Kini, 1994] проводится исследование влияния перехода к публичной собственности через размещение акций на бирже на последующую эффективность компании. Авторами отмечается снижение операционной эффективности компании после IPO, что сопровождается снижением коэффициентов EPS, P/E, M/B. Авторы обнаружили значимую положительную связь между долей, удерживаемой первоначальным владельцем при размещении, и последующей эффективностью компании и не обнаружили никакой связи между последующей эффективностью и величиной недооценки.

Авторы приводят ссылку на работу Дэжорж и Цэкбаузэр [Degeorge \& Zeckbauser, 1993], исследовавших влияние обратных LBO на последуюшую за ними эффективность компании.

Для измерения эффективности используется операционная отдача на активы (ROA) и отдача операционных денежных потоков на активы (operating cash-flow return on assets) до и после размещения как с корректировкой на индустрию, так и без нее.

Авторы отмечают, что эффективность компаний в терминах данных показателей снижается после IPO, но при этом продажи и капитальные расходы активно растут (рост даже выше отраслевого).

В итоге авторы приходят к выводу, что низкая эффективность после IPO не оправдывает высоких коэффициентов М/B и P/E, по которым размещаются компании при IPO, и формулируют гипотезу о том, что инвесторы систематически переоценивают потенциал роста доходов компании.

Авторы предлагают три гипотезы, объясняющие феномен. Первая гипотеза заключается в том, что при публичной собственности возникают повышенные агентские издержки, изложенные в работе Дженсен и Меклинг [Jensen \& Meckling, 1976]. Полученные в результате IPO средства расходуются менеджерами на проекты с отрицательным NPV. Вторая гипотеза состоит в том, что менеджеры используют специальные манипуляции для приукрашивания отчетности при выходе на биржу (window-dressing). Третья гипотеза такова, что изначальные акционеры выбирают время для выпуска компании на биржу в момент чрезвычайно высоких доходов в отрасли, что приводит к их завышенной оценке. На самом деле акционеры знают, что уровни прибыльности на таких пиках не поддерживаемы в долгосрочном периоде.

Базой для рассмотрения проблемы снижения эффективности после IPO является предпосылка об асимметрии информации и конфликте интересов прежних владельцев-менеджеров и новых акционеров.

Авторы приводят ссылку на работы Каплан [Kaplan, 1989], Мускарелла и Ветсаупенс [Muscarella \& Vetsuypens, 1990], и Смит [Smith, 1990], в которых отмечается повышение эффективности компании после 
MBO и LBO (противоположных процессов IPO) в результате снижения агентских издержек (конфликта интересов).

В работе упоминается модель Штайн [Stein, 1989], которая предсказывает, что при эффективности рынка рациональные инвесторы предвидят манипуляции менеджеров и их желание выйти во время пика. Учет желаний менеджеров инвесторами должен приводить к равновесию (по Нэшу) и давать требуемую доходность. Но в работе Риттер [Ritter, 1991] и Лафран и Риттер [Loughran \& Ritter, 1995] приводится противоположное эмпирическое наблюдение: инвесторы систематически получают более низкую доходность в долгосрочном периоде по акциям IPO.

Вывод о том, что после IPО более эффективно работают компании, в которых первоначальными акционерами сохраняется большая доля при IPO, согласуется с гипотезой агентских издержек Дженсен и Меклинг [Jensen \& Meckling, 1976] и гипотезой сигнальных эффектов Лиланд и Пайль [Leland \& Pyle, 1977].

Авторы не могут опровергнуть, но и не могут подтвердить сигнальную гипотезу недооценки, изложенную в работах Ален и Фоулхабэр [Allen \& Faulhaber, 1989], Гринблатт и Хванг [Grinblatt \& Hwang, 1989], Уэлч [Welch, 1989]. Данная гипотеза заключается в том, что фирмы более высокого качества сигнализируют инвесторам через недооценку, так как при хорошем качестве цена при дальнейшем раскрытии информации будет повышаться, и изначальные акционеры смогут продать дополнительные акции по большей цене. Согласно этой гипотезе, начальные акционеры хороших компаний удерживают как можно большую долю в компании.

В работе Меггинсон и Вайс [Megginson \& Weiss, 1991] оценивается влияние венчурных фондов на компании, выходящие на IPO. Для компаний, которые поддерживаются венчурными фондами отмечена меньшая недооценка при выпуске и меньший спрэд андеррайтера, что снижает потери недополученных средств при IPO. Также отмечается удержание большей доли венчурными фондами после IPO. Авторы рассматривали период 1983-1987 годов и проводили корректировки в соответствии с размером и отраслью деятельности компании.

Авторами проверяется гипотеза формальной сертификации, изложенная в работе Бут и Смит [Booth \& Smith, 1986], на базе которой строили модели по асимметричной информации Джэймс [James, 1990], Блэкуэлл, Марр и Спиви [Blackwell, Marr, \& Spivey, 1990] и Барри, Мускарелла, Пиви и Ветсаупенс [Barry, Muscarella, Peavy, \& Vetsuypens, 1991]. Исследование базируется на основных работах в области асимметрии информации на финансовом рынке при IPO и роли аудиторов и инвестиционных банкиров в устранении данной асимметрии: Дэанжело [DeAngelo, 1981], Битти и Риттер [Beatty \& Ritter, 1986], Титман и Труман [Titman \& Trueman, 1986], Джонсон и Миллер [Johnson \& Miller, 1988], 
Картер [Carter, 1990], Саймон [Simon, 1990], и Картер и Манастер [Carter \& Manaster, 1990].

Авторами используется методология парного сравнения, при которой берутся компании одной и той же отрасли с поддержкой венчурного фонда и без нее, и подтверждается, что по компаниям с участием и поддержкой венчурных фондов недооценка ниже, и спрэд, требуемый андеррайтером ниже, что в итоге дает больше поступлений при

IPO фирмам с поддержкой венчурного фонда. В результате подтверждается гипотеза, что венчурный фонд выступает в роли посредника, снижающего асимметрию информации и посылающего позитивный сигнал инвесторам. Также подтверждается, что компании с поддержкой венчурных фондов способны привлечь более престижных аудиторов и андеррайтеров. Роль медиаторов венчурных фондов, снижающих асимметрию информации, также подтверждается через большее участие институциональных инвесторов при IPO этих компаний и более ранний их выход на биржу, чем компаний без поддержки. Сохранение венчурным фондом существенной доли после IPO также передает позитивный сигнал инвесторам.

\section{Преимущества и недостатки публичного размещения}

Выгоды, приобретаемые при выходе на IPO компаний, многочисленны. Главной причиной выхода компании на IPO считается привлечение капитала непосредственно во время размещений и облегчение привлечения капитала в будущем. Выход компании на IPO действительно дает доступ к небанковским средствам, однако с размещением связаны и другие преимущества. Часто компании с большим объемом долга вынуждены платить высокие проценты банку. Выход компании на IPO не только приводит к уменьшению рычага, но и к снижению затрат на привлекаемый долг вследствие раскрытия информации и получения альтернативного источника финансирования. Переговорная сила компании с банками и финансовыми институтами возрастает. Выход на IPO привлекателен и для акционеров компании, так как дает им возможность продать часть доли и диверсифицировать свой портфель. Также среди выгод публичного размещения можно назвать повышение спроса на акции, улучшение имиджа компании и корпоративной культуры, диверсификацию инвестиционного портфеля инвестора.

\section{Преодоление финансовых ограничений}

Ключевым преимуществом публичного размещения является получение нового источника финансирования. Нередко в условиях асимметричной информации компании сталкиваются с очень высокими ставками по банковским кредитам. В таких условиях компании с высокой 
инвестиционной активностью и большим финансовым рычагом захотят выйти на IPO для финансирования инвестиций или сокращения величины долга.

Увеличение переговорной силь в отношениях с банком

В качестве единственного заемщика банк может воспользоваться своим монопольным положением к доступу к информации. Выходя на фондовый рынок, компания раскрывает информацию потенциальным инвесторам, тем самым расширяя их круг и увеличивая предложение капитала, что ведет к возможности получать более дешевый капитал. Именно к такому выводу приходит в своей статье Раджан [Rajan, 1992]. При этом вероятность выхода на IPO выше для компаний с высокими ставками процента по долгу. После IPO ставки процента для компании должны падать, а размер кредитной линии возрастать.

Уменьшение финансового рычага

Уменьшение финансового рычага приводит к снижению рисковости портфелей акционеров, даже если они не продают акции во время IPO.

Использование окон возможностей

Если компании в отрасли переоценены, то это создает дополнительные стимулы у компаний выйти на IPO, чтобы использовать благоприятную конъюнктуру и привлечь большее количество капитала, а также увеличить стоимость бизнеса.

Повышение узнаваемости среди инвесторов и ликвидности акичий

При продаже доли в частной компании сторона, инициировавшая сделку, несет большие издержки по поиску информации. Приобретение акций публичной компании, напротив, дешевле для большого количества мелких инвесторов. Акции публичной компании более ликвидны и могут быть легко перепроданы. Если компания хочет продать акции большому количеству разрозненных инвесторов, то лучше выходить на публичное размещение. При этом высокая ликвидность ведет к более высокой цене продажи акции. Если же компания желает оставаться частной, то лучше привлекать капитал через минимальное количество крупных инвесторов, тем самым минимизируя издержки приобретения информации и мониторинга. В противном случае она будет вынуждена смириться с избыточным мониторингом

Ликвидность компании при выходе на IPO повышается, так как большое количество инвесторов узнает про компанию и получает о ней легкодоступную информацию. При этом, как отмечал Мертон [Merton, 1987], цена акции тем выше, чем больше инвесторов знают о существовании компании. Подтверждают этот вывод и работы Кадлек и 
МакКонелл [Kadlec \& McConnell, 1994], показывая, что компании получают 5\% сверх средней доходности, если уже котирующиеся компании заявляют о выходе на Нью-Йоркскую биржу.

\section{Диверсификация портфеля акцииоеров}

Одним из важных мотивов выхода на IPO может быть желание инвесторов диверсифицировать свой портфель. При этом диверсификация может быть достигнута двумя способами. Это может быть непосредственная продажа акций компании, выходящей на IPO, и приобретение акций других компаний или использование капитала, привлеченного компанией на IPO, для приобретения доли в других бизнесах. Если диверсификация портфеля является одной из важнейших причин выхода на IPO, то, согласно работе Пагано [Pagano, 1993], на IPO должны выходить наиболее рисковые компании, и во время размещения собственники захотят продавать крупные пакеты акций.

IPO также может быть первым шагом на пути к продаже компании. Зингалес [Zingales, 1995] утверждает, что продажа небольшого пакета на IPO может увеличить излишек акционера при будущей продаже контрольного пакета.

\section{Дисциплина рынка}

IPO может снизить проблему агентских издержек в отношениях «акционер-менеджер», так как рынок ценных бумаг дает дополнительные инструменты контроля менеджеров. Угроза захвата компании рейдерами, которые смогут обеспечить лучшее управление компанией, дисциплинирует менеджеров. Шлайфер и Вышни [Shleifer \& Vishny, 1986] утверждают, что это особенно верно в случае, если рейдеры могут получить большую долю собственности.

Кроме того, как показывают Холмстром и Тироль [Holmstrom \& Tirole, 1993], при выходе на IPO собственник имеет возможность внедрить более эффективную систему вознаграждения менеджеров. Например, при последующих публичных размещениях акций компании могут стимулировать работу менеджмента с использованием опционов.

\section{Издержкки IPO}

Однако при выходе на IPO компании принимают во внимание не только многочисленные выгоды, но также и издержки публичного размещения. Среди издержек имеются не только расходы, связанные непосредственно с размещением, но и издержки раскрытия информации. Существуют также и издержки, возникающие вследствие асимметрии информации.

Неблагоприятный отбор и моральный риск 
Если инвесторы обладают несовершенной информацией, то у «некачественных» компаний существуют сильные стимулы для выхода на IPO. Рок [Rock, 1986] и многие другие исследователи отмечают, что в результате присутствия на рынке большого числа таких фирм снижается цена для всех компаний. Развитие исследований в области несовершенной информации объясняет проблему недооценки. Эффект от издержек неблагоприятного отбора сильнее для маленьких и молодых компаний, информация о которых является менее доступной по сравнению с крупными компаниями. Значит, вероятность выхода на IPO положительно зависит от размера и возраста компании, как показали в своей работе Шэмманур и Фулгири [Chemmanur \& Fulghieri, 1994]. Авторы отмечают, что первичное публичное размещение с продажей множеству инвесторов влечет за собой высокие издержки на приобретение информации, так как инвесторы дублируют усилия друг друга, но при этом риски распределены эффективно. В случае продажи акций одному венчурному капиталисту издержки на получение информации минимизируются, однако риск распределен неэффективно, что приводит к высокой премии за риск. Таким образом, частное финансирование больше подходит молодым, быстрорастущим компаниям, a публичное размещение акций - более зрелым, известным компаниям. К такому же выводу приводят агентские модели, где акционер с контрольным пакетом получает частные выгоды за счет внешних инвесторов. Даймондс [Diamonds, 1991] утверждает, что проблема морального риска приводит к тому, что маленькие компании берут займы у банков, которые ограничивают оппортунистическое поведение с помощью мониторинга, a большие компании с хорошей репутацией имеют возможность занимать на открытом рынке.

Другим важным следствием проблемы морального риска и неблагоприятного отбора является положительная зависимость между долей, сохраненной акционерами, и доходностью компании после IPO. Как уже упоминалось выше, Лиланд и Пайль [Leland \& Pyle, 1977] показали, что для предотвращения подачи неверного сигнала акционеры вынуждены оставлять у себя слишком большую долю и тем самым нести издержки в виде упущенной диверсификации. В то же время классическая работа Дженсен и Меклинг [Jensen \& Meckling, 1976] говорит, что большая доля изначального акционера приводит к повышению стимулов для извлечения частных выгод, что снижает стоимость компании для частных инвесторов. Для уменьшения издержек из-за недооценки крупные собственники стремятся уменьшить предлагаемую долю во время IPO, а по мере роста цены будут постепенно продавать акции.

\section{Административные расходыл}

Помимо проблемы недооценки во время размещения компания несет издержки, напрямую связанные с размещением: расходы на 
андеррайтера, регистрационные сборы и т.д. Кроме единовременных издержек на размещение существуют и ежегодные расходы на аудит, сертификаты, раскрытие бухгалтерской информации, биржевые сборы. Многие из этих расходов растут непропорционально размеру компании и потому более обременительны для маленьких компаний. Риттер [Ritter, 1987] оценил, что для США фиксированные расходы равны $\$ 250$ тыс. и переменная часть составляет 7\% от стоимости выпуска IPO.

\section{Потеря конфиденциальности}

Требования по раскрытию информации ведут к потерям для компании в терминах конкурентоспособности. Секретность информации (объемы R\&D, маркетинговые стратегии) может быть критична для сохранения конкурентного преимущества. Также необходимость раскрытия информации уменьшает возможности экономии на налогах. Как указывают в своих работах Кампелл [Campell, 1979] и Йоша [Yosha, 1995], высокие издержки потери конфиденциальности могут снижать вероятность выхода фирмы на IPO.

Баттачариа и Чиза [Bhattacharya \& Chiesa, 1994] пришли к выводу, что при высоких расходах на R\&D компании будут склонны устанавливать надежные закрытые отношения с кредиторами, чтобы избежать утечки информации. Если гипотеза верна, то для высокотехнологичных отраслей вероятность выхода на IPO должна быть, согласно такой логике, ниже.

\section{Истинные причины выхода компании на ІРО: результаты эмпирических исследований}

В своей статье “Why Do Companies Go Public? An Empirical Analysis” Пагано, Панетта и Зингалес [Pagano, Panetta, Zingales, 1998] пытаются выявить истинные причины выхода компаний на IPO. Для того чтобы понять стимулы компании при первичном публичном размещении, исследуются показатели деятельности компании до и после первичного публичного размещения. Авторы статьи рассматривают решения об инвестициях и финансовой политике компании после IPO, так как они могут помочь раскрыть те мотивы выхода на IPO, которые невозможно определить по состоянию компании до размещения.

Работа проводится на основе данных об итальянских компаниях в 1982-1992 годах. Для выявления причин, повлиявших на выход на IPO, строится probit-модель, где вероятность публичного размещения зависит от следующих факторов:

1) размера компании (объема продаж);

2) капитальных вложений;

3) темпов роста;

4) доходности активов; 
5) среднего отношения Market-to-Book в отрасли, определяющего состояние всей отрасли;

6) цены капитала для компании относительно средней цены кредита и

7) индекса концентрации банковских услуг, зависящих от количества банков, у которых компания может занимать.

Для анализа показателей компании после выхода с публичным размещением авторы строят регрессию для каждого показателя:

1) ROA;

2) капитальные вложения;

3) финансовый рычаг;

4) инвестиции;

5) привлечение собственного капитала;

6) привлечение заемного капитала;

7) выплаты дивидендов;

8) уплата налога;

9) темпы роста;

10) ставки процентов;

11) индекс концентрации услуг банка;

12) количество банков-кредиторов.

Для анализа каждого из показателей используется модель с фиксированным эффектом (FE) вида:

(8) $y_{i t}=\alpha+\sum_{j=0}^{3} \beta_{j} I P O_{t-j}+\beta_{4} I P O_{t-n}+\sum_{j=0}^{3} \gamma_{j} Q U O T_{t-j}+u_{i}+d_{t}+\varepsilon_{i t}$,

где $\mathrm{u}_{\mathrm{t}}$ - эффект для фирмы, $\mathrm{d}_{\mathrm{t}}$ - эффект для каждого года после размещения, $\mathrm{IPO}_{\mathrm{t}-\mathrm{j}}$ - дамми для года, когда компания вышла на IPO, IPO - дамми, равная 1, если компания вышла на IPO более 3 лет назад, QUOT - дамми, равная 1, если компания удовлетворяла требованиям выхода на биржу.

Авторы показывают, что основными факторами, влияющими на вероятность выхода на IPO, являются большие возможностями роста у компаний в отрасли и большая потребность в дополнительном капитале для инвестиций. Также предприниматели используют удачную конъюнктуру на рынке для повышения стоимости компании и привлечения средств. Вероятность выхода на IPO положительно зависит от размера компании, темпов ее роста и прибыли. Существует различие в мотивах выхода на IPO для независимых компаний и дочек крупных компаний, имеющих доступ к дешевому капиталу материнской компании. Для независимых компаний выход на IPO более вероятен после периода осуществленных крупных инвестиций и периода бурного роста, т.к. IPO ведет к снижению величины рычага и инвестиций. Таким образом, для них IPO - способ изменения структуры капитала компании. Для 
дочерних компаний IPО является возможностью получить новые средства и использовать «окна возможностей».

Анализ изменения показателей компании после выхода на IPO выявил, что после IPO наблюдается значительное снижение прибыли, что может быть следствием манипулирования отчетностью (window-dressing) до IPO или следствием проблемы неблагоприятного отбора. Вопреки предсказаниям, инвестиции снижаются после выхода на IPO, что противоречит мотиву удовлетворения потребности в капитале для финансирования роста. При этом уменьшается рычаг, а значит, средства, привлеченные на IPO, используются в основном для уменьшения долга.

Анализ также показал, что ставка банковского кредитования после IPO снижается, так же как и концентрация долга. Компании увеличивают налоговые выплаты. Существенным мотивом выхода компании на IPO оказывается желание крупных собственников продать часть своей доли, что подтверждается более высокой вероятностью смены контроля через 3 года после IPО по сравнению с другими компаниями в отрасли.

К совершенно другому выводу приходят Ким и Вайсбах [Kim \& Weisbach, 2005] в статье “Do Firms Go Public to Raise Capital?”. В работе получен результат, что привлечение капитала — важная причина выхода на IPO. Исследователи выявляют истинные мотивы выхода на IPO, сравнивая компании, вышедшие на IPO с продажей новых выпускаемых акций, с компаниями, в которых акционеры продают часть собственных ранее выпущенных акций.

Используются данные 16958 компаний из 38 стран, вышедших на IPO. Как показывает исследование, структура первичного размещения сама по себе может выявлять причины, побудившие компанию выйти с первичным публичным размещением акций. Если компания размещает акции нового выпуска во время IPO, то это увеличивает объем акционерного капитала, привлекает дополнительные средства и изменяет финансовую структуру компании. Размещение акций, принадлежащих первоначальным акционерам, не влечет за собой увеличения капитала компании, а обусловлено желанием собственников диверсифицировать свои инвестиции и повысить ликвидность своего капитала.

Для того, чтобы выяснить, как показатели компании - активы, товарно-материальные запасы, материальные внеоборотные активы, капитальные вложения, расходы на $\mathrm{R} \& \mathrm{D}$, запасы наличности, изменение долгосрочного долга - зависят от структуры выпуска, строятся два вида уравнения с фиксированным эффектом для каждого показателя:

(9)

$$
Y=\beta_{1} \times \ln \left[\left(\frac{\text { primary_capital }}{\text { total_assets }_{0}}\right)+1\right]+\beta_{2} \times \ln \left[\left(\frac{\text { secondary_capital }}{\text { total_assets }_{0}}\right)+1\right]+\beta_{3} \times \ln \left[\text { total_assets }_{0}\right]+F E+\varepsilon
$$


(10)

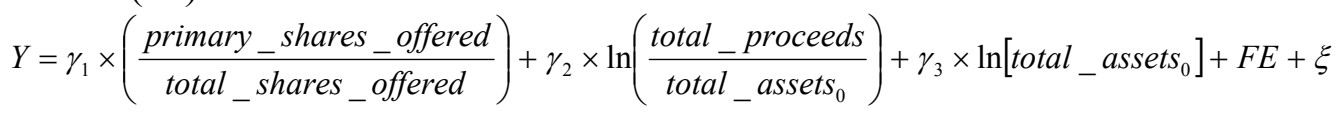

где FE - дамми для года, страны и отрасли.

Авторы приходят к выводу, что выход компании на IPO с акциями нового выпуска связан с последующим ростом инвестиций, ростом выплат по долгу, ростом наличности, дальнейшим привлечением капитала посредством последующих публичных размещений. Так как большинство компаний выходят именно с акциями нового выпуска, то привлечение нового капитала для таких компаний является важным мотивом выхода на IPO. Авторы показали, что в этом случае привлеченный капитал главным образом расходуется на $\mathrm{R} \& \mathrm{D}$, капитальные вложения и сокращение долгосрочного долга. Размещая на IPO акции первоначальных собственников, компания не привлекает дополнительных средств. Стимулом выхода на IPO для таких фирм служит желание собственников повысить ликвидность своей доли.

Хаугбегарт и Хулле [Huygbegaert \& Hulle, 2006] проводят очень похожее на работу Ким и Вайсбах [Kim \& Weisbach, 2005], но независимое исследование.

Рассматривается структура размещения акций бельгийских компаний, выходящих на IPO, с целью выявления истинных мотивов выхода на IPO. Авторы с помощью регрессионного анализа методом МНК и двухшаговым МНК выяснили, как издержки и выгоды выхода на IPO влияют на структуру предложения акций на IPO. В этом исследовании показатели деятельности компании являются объясняющими переменными, а доля первичных и вторичных акций при размещении зависимыми.

Регрессии дают следующие результаты:

- Доля акций нового выпуска больше, если компании нуждаются в дополнительном финансировании, хотят использовать возможности роста, снизить долю долга, хотят использовать положительную конъюнктуру фондового рынка. Молодые, быстрорастущие компании чаще выходят именно с акциями нового выпуска.

- Регрессионный анализ IPO акций первоначальных акционеров показывает, что вопреки ожиданиям диверсификация не является важной причиной выхода на IPO и акционеры крупных известных компаний продают большую долю своих акций, чем акционеры более рисковых компаний.

В результате своего исследования авторы пришли к выводам, что часто собственники выводят компанию на IPO с целью ее дальнейшей продажи. При этом вероятность смены контроля меньше у фирм с высоким рычагом и с высокой доходностью, и выше для компаний, выходящих на IPO только с акциями первоначальных акционеров. 
Исследования показывают, что мотив повышения ликвидности через размещение акций снижает стимулы компании использовать привлекаемый капитал для роста, поэтому компании выходят на IPO с небольшим количеством акций нового выпуска и большой долей акций первоначальных акционеров. Известные крупные компании предлагают на IPO только вторичные акции. Для таких компаний мотив использования «окон возможностей» является очень важным и существенно влияет на объем размещения. Часто компании, выходящие на IPO только с новым выпуском, после повышения ликвидности вновь выходят на рынок для продажи акций по более высокой цене.

\section{Когда компании выходят на IРО?}

Традиционно считается, что компании выходят на IPO, когда достигают определенного размера. То есть IPО является одной из стадий роста компании. В работах Ибботсон и Джаффе [Ibbotson \& Jaffe, 1975], Риттер [Ritter, 1980] и других авторы показывают, что выходы компаний на IPO происходят волнами. Классические исследования показывают, что время выхода компании на IPO обусловлено желанием менеджеров воспользоваться преимуществами IPO на растущем рынке и разместить акции по привлекательным ценам. Эмпирические исследования преимуществ растущего рынка изучают влияние текущей ситуации на фондовом рынке (Лукас и МакДональд [Lucas \& McDonald, 1990]), влияние благоприятной ситуации в отрасли (Пагано и пр. [Pagano et al., 1998]), прогнозы общей ситуации на рынке ценных бумаг (Лукас и Макдональд, [Lucas \& McDonald, 1990]), прогноз для отрасли (Лоури, [Lowery, 2002]), а также условия, предшествующие размещению (Риттер и Уэлч [Ritter \& Welch, 2002]).

C помощью анализа долгосрочных доходностей Риттер [Ritter, 1991] и Лафран и Риттер [Loughran \& Ritter, 1995] показывают, что компании выбирают время выпуска так, чтобы использовать «окна возможностей» для получения наиболее привлекательных цен акций.

С другой стороны, время выхода обусловлено состоянием рынка IPO. Лоури и Швэрт [Lowery \& Schwert, 2002] доказывают, что высокая доходность недавних размещений акций в первый день торгов побуждает другие компании выходить на IPO. Чо, Мазулис и Нанда [Choe, Masulis, \& Nanda, 1993] приходят к выводу, что компании предпочитают размещать акции в периоды, когда другие хорошие компании выходят на IPO.

В-третьих, в работах Чо, Мазулис и Нанда [Choe, Masulis, \& Nanda, 1993] и Лоури [Lowery, 2002] авторы утверждают, что выход на IPO происходит в момент, когда компании достигают определенной стадии бизнес-цикла и испытывают необходимость во внешнем финансировании роста. 
Самое последнее исследование в этом направлении - работа Пастор и Веронеси [Pastor \& Veronesi, 2005], в которой разрабатывается модель оптимального времени для IPO в зависимости от рыночных условий. Рыночные условия определяются тремя параметрами: ожидаемая доходность рынка, ожидаемая общая прибыльность, неопределенность относительно доходности IPO свыше рыночной. По мнению авторов, волны IPO объясняются снижением в ожидаемой рыночной доходности, ожиданиями повышения общей прибыльности или повышением неопределенности относительно будущей средней прибыльности IPO. В результате тестирования модель подтверждается и отмечается, что волны IPO следуют за высокой доходностью на рынке и предшествуют низким доходностям.

Авторы исследуют феномен, отмеченный Ибботсон и Джаффе [Ibbotson \& Jaffe, 1975], о неравномерности выхода компаний с IPO (в одни годы выходит очень много, в другие совсем мало). Авторы предлагают альтернативный взгляд на данный феномен в отличие от известной гипотезы о том, что компании выбирают моменты, когда рынок переоценивает, а инвесторы этого не замечают (исследования Риттер [Ritter, 1991]; Лафран, Риттер и Ридквист [Loughran, Ritter, \& Rydqvist, 1994]; Лафран и Риттер [Loughran \& Ritter, 1995]; Раджан и Серваес [Rajan \& Servaes, 1997, 2003]; Пагано, Панетта и Зингалес [Pagano, Panetta, \& Zingales, 1998]; Бэйкер и Вурглер [Baker \& Wurgler, 2000]; Лоури [Lowry, 2003]).

Согласно авторам, именно предшествующее изменение цен на акции, а не абсолютный уровень цен, вызывают бум IPO.

Стюарт Майерс [Stewart Myers, 2000] в работе "Outside Equity" подходит к проблеме с точки зрения прав собственности. Пусть стоимость первоначальных нематериальных активов, которые вкладывает предприниматель в создание бизнеса, должна быть выявлена в процессе предварительного R\&D, которое финансируют внешние инвесторы. Как только выявляется истинная ценность нематериального актива, он легко может быть захвачен инвесторами. Если для предпринимателя возникает угроза потери контроля над своей идеей или другим нематериальным активом, то он скорее всего учредит небольшую компанию самостоятельно. В дальнейшем собственник привлечет капитал при выходе на IPO, после которого множеству разрозненных инвесторов будет сложнее захватить контроль над компанией. Во время публичного размещения переговорная сила внешних инвесторов по отношению к инсайдерам падает. Так, автор объясняет, почему высокотехнологичные компании выходят на IPO на ранних стадиях развития. Правильным временем для выхода на IPO будет момент, когда собственные средства уже израсходованы, однако вся прибыль от работы компании еще не получена и стоимость компании не может быть верно оценена внешними инвесторами. 
Беннинга, Хэльмантель и Зариг [Benninga, Helmantel \& Sarig, 2005] используют теоретический подход к исследованию времени выхода компании на IPO. Большинство работ по проблеме выгод и издержек предполагает, что выбор о выходе компании на IPO осуществляется в результате взвешивания выгод и издержек один раз. При этом, если компания решила не размещать свои акции на открытом рынке сегодня, это не исключает возможности принятия решения о выходе на IPO в будущем. Более того, компания также может принять решение об отзыве акций и стать опять частной компанией. Авторы моделируют время выхода на IPO, фокусируясь исключительно на вопросах собственности. Собственник выводит компанию на IPO только в том случае, если внешние инвесторы с более диверсифицированным портфелем готовы заплатить за денежные потоки компании с заданным риском больше, чем сам собственник. При этом публичность компании влечет за собой некоторые издержки/уменьшение выгод от закрытости компании. Баланс выгод и издержек от первичного размещения и определяет решение о размещении акций. Более высокая цена, которую готовы заплатить инвесторы, включает в себя такие выгоды от размещения, как увеличение ликвидности акций, выгоды мониторинга, способность рынка акций указывать на удачи и промахи менеджмента. В качестве издержек публичного размещения авторы указывают на приведенные в работе Дженсен [Jensen, 1986] издержки разделения собственности и контроля. Издержки также включают в себя рост административных издержек и рост издержек из-за раскрытия инсайдерской информации. Модель строится следующим образом: $u>1>d$.

- Денежный поток $C F$ в периоде $\mathrm{t}+1$ может быть $u C F$ или $d C F$, при

- $P B$ отражает издержки публичной компании и равен разности денежных потоков публичной и частной компании.

- В случае публичной компании ее денежный поток равен $C F_{0}$ $u^{s} d^{t-s}$, для частной компании он равен $C F_{0} u^{s} d^{t-s}+P B$.

- Рассматривается два сценария - $u$ для хорошего состояния и $d$ для плохого.

- Так как внешние инвесторы имеют возможность диверсифицировать портфель, то оценка риска и компании будут различаться в зависимости от статуса компании. И собственник, и внешний инвестор могут альтернативно вложить средства в безрисковый актив

$$
p_{u}+p_{d}=q_{u}+q_{d}=\frac{1}{1+r}=\frac{1}{R},
$$

где $\mathrm{p}$ - оценка частной компании, a $\mathrm{q}$ - публичной компании при реализации сценария u и $\mathrm{d} . \mathrm{p}_{\mathrm{u}}<\mathrm{q}_{\mathrm{u}}, \mathrm{p}_{\mathrm{u}}>\mathrm{q}_{\mathrm{u}}$. 
- В каждый момент времени собственники принимают решение относительно выхода на IPO, исходя из максимизации стоимости компании

$$
V(C F)=\max \left\{\begin{array}{c}
p_{u}(u C F+P B+V(u C F))+p_{d}(d C F+P B+V(d C F)) \\
q_{u}(u C F+V(u C F))+q_{d}(d C F+V(d C F))
\end{array}\right\}
$$

Оптимальное время выхода определяется из динамики денежных потоков компании. При этом допускается изменение решений в будущих периодах. Владельцы компании выпускают акции в периоды больших денежных потоков компании, и эти периоды совпадают с периодами высоких цен на фондовом рынке, так как денежные потоки компаний в одной отрасли сильно коррелированны. В периоды маленьких денежных потоков компании отзывают акции.

Результаты, полученные авторами, хорошо соотносятся с выводами Хальпэрн и пр. [Halpern et al., 1999]. Авторы объясняют загадку активизации выхода фирм на IPO в периоды бумов, обозначенную в работе Риттер [Ritter, 1984].

Работа также помогает взглянуть на проблему низкой отдачи от вложений на стадии IPO с точки зрения денежных потоков. Авторы объясняют проблему существованием возможности у компаний отозвать акции при уменьшении денежных потоков до уровня, когда выгоды диверсификации более не покрывают издержек публичного размещения. Доля привлеченного на фондовом рынке капитала у компаний, только что вышедших на IPO, больше по сравнению с размером компании, а значит, риск отзыва акций меньше. Именно это является причиной низкой доходности акций сразу после выпуска. Такой вывод подтверждает мнение Экбо и Норли [Eckbo \& Norli, 2000] о том, что выходящие на IPO компании менее рискованные, а значит, их акции должны приносить меньшую доходность.

Брау и Фосетт [Brau \& Fawcett, 2006] используют новый подход к исследованию проблемы - опросы CFO (Chief Financial Officer), на основании которых авторы выявляют точку зрения компании по вопросам первичного размещения акций. Объектом исследования являются проблемы мотивов выхода на IPO, определение времени выхода, выбор компанией андеррайтера, недооценка при выпуске, сигнальные эффекты, вопросы процесса размещения и решения компании оставаться закрытой частной компанией. Используются данные анкет 336 фирм, среди которых 87 компаний, успешно вышедших на IPO, 212 достаточно крупных, но решивших не выходить на IPO, и 37 компаний, которые прекратили процесс выхода. Для проверки данных опроса взяты данные базы EDGAR. В вопроснике предлагалось оценить влияние факторов на 
принятие решения о выходе на IPO по пятибалльной шкале. Важность фактора оценивалась по среднему значению.

Согласно полученным результатам, CFO считают самой важной причиной выхода на IPO создание акций для дальнейшего их использования при поглощениях. А классические факторы снижения стоимости капитала и "реcking order» являются менее значимыми при первичном размещении акций. Для высокотехнологичных компаний выход на IPO вообще не объясняется финансовыми соображениями, а происходит в основном для улучшения репутации компании.

Исследование также затронуло волнообразную активность компаний по выходу на IPO. Брау и Фосетт [Brau \& Fawcett, 2006] показывают, что при выходе на IPO финансовые директора принимают во внимание ситуацию на рынке и отраслевую доходность фондового рынка и уделяют меньше внимания ситуации на рынке IPO.

Важными факторами выбора андеррайтера СFO считают его репутацию, качество работы исследовательских подразделений и знание отрасли. СFО считают, что размещение акций инсайдеров во время IPO (spinning) играет более важную роль при выборе андеррайтера в больших компаниях, нежели в маленьких. Для CFO, которые выбирают известных андеррайтеров, большое значение имеет репутация, качество услуг, экспертное знание отрасли и наличие институциональных инвесторов среди клиентов андеррайтера. Компании, выбравшие менее известных и престижных андеррайтеров, больше внимания уделяют требуемой комиссии за размещение, количеству мелких клиентов и расценкам андеррайтера.

Исследование также показывает, что CFO достаточно хорошо осведомлены о проблеме недооценки акций при выпуске (underpricing) и считают, что недооценка компенсирует риск, принимаемый на себя инвесторами в первый день размещения. Второй важной причиной существования недооценки акций при выпуске считается желание андеррайтера привлечь внимание институциональных инвесторов.

Самым важным положительным сигналом при выходе на IPO является прибыль в предыдущих периодах. Компании принимают решение не выходить на IPO главным образом из соображений сохранения контроля. CFO также опасаются неблагоприятных рыночных условий. Авторы пришли к заключению, что вышедшие на IPO и не выходившие компании по-разному оценивают факторы, влияющие на принятие решения о первичном размещении.

Сводная информация по основным исследованиям в области анализа IPO с точки зрения компании представлена в таблице 2. 
Таблица 3.

Основные исследования тематики IPO с точки зрения компании

\begin{tabular}{|c|c|c|c|}
\hline Авторы и год & Основные проблемы & Метод исследования & Основные результаты \\
\hline $\begin{array}{l}\text { William L. } \\
\text { Megginson \& } \\
\text { Kathleen A. Weiss, } \\
1991\end{array}$ & $\begin{array}{l}\text { Влияние присутствия } \\
\text { венчурных фондов на IPO, } \\
\text { оценка роли венчурных фондов } \\
\text { как снижающих асимметрию } \\
\text { информации. }\end{array}$ & $\begin{array}{l}\text { Оценка величины } \\
\text { недооценки и комиссий } \\
\text { андеррайтеров для компаний } \\
\text { с поддержкой венчурных } \\
\text { фондов и без нее. }\end{array}$ & $\begin{array}{l}\text { Имеется подтверждение меньшей недооценки и более низких } \\
\text { комиссионных затрат на размещение IPО для фирм с поддержкой } \\
\text { венчурных фондов, также данные фирмы имеют доступ к более } \\
\text { престижным андеррайтерам и аудиторам. Венчурные фонды } \\
\text { сохраняют существенную долю в компании после IPO. }\end{array}$ \\
\hline $\begin{array}{l}\text { William L. } \\
\text { Megginson \& } \\
\text { Kathleen A. Weiss, } \\
1991\end{array}$ & $\begin{array}{l}\text { Влияние рыночных условий на } \\
\text { решение о выходе с IPО и на } \\
\text { волны IPО. }\end{array}$ & $\begin{array}{l}\text { Разработана теоретическая } \\
\text { модель решения о выходе на } \\
\text { IPО. }\end{array}$ & $\begin{array}{l}\text { Волны ІРО следуют за периодом низкой ожидаемой доходности, } \\
\text { роста неопределенности и сопровождаются высоким уровнем } \\
\text { общей прибыльности. Подтверждается гипотеза, что инноваторы, } \\
\text { генерируя постоянно идеи, выжидают момента возникновения } \\
\text { благоприятных рыночных условий и выходят именно в такие } \\
\text { моменты времени. }\end{array}$ \\
\hline $\begin{array}{l}\text { Bharat A. Jain \& } \\
\text { Omesh Kini, } 1994\end{array}$ & $\begin{array}{l}\text { Эффективность компании } \\
\text { после IPО, проверка } \\
\text { сигнальной гипотезы } \\
\text { недооценки Лиланда и Пайла, а } \\
\text { также теории агентских } \\
\text { издержек Дженсена и } \\
\text { Меклинга. }\end{array}$ & $\begin{array}{l}\text { Оценка и сравнение отдачи } \\
\text { на активы за год до и в } \\
\text { последующие годы после } \\
\text { IPO, оценка динамики P/E, } \\
\text { EPS, M/B после IPO. }\end{array}$ & $\begin{array}{l}\text { Наблюдается отрицательная динамика и снижение эффективности } \\
\text { по операционным показателям, сигнальная гипотеза недооценки } \\
\text { не подтверждается и не отвергается. Наблюдения снижения } \\
\text { эффективности согласуются с теорией агентских издержек } \\
\text { Дженсена и Меклинга. }\end{array}$ \\
\hline $\begin{array}{l}\text { Marco Pagano, } \\
\text { Fabio Panetta, } \\
\text { Luigi Zingales, } \\
1998\end{array}$ & $\begin{array}{l}\text { Факторы, влияющие на } \\
\text { решение о выходе на IPО, и как } \\
\text { IPО влияет на последующие } \\
\text { решения об инвестициях и } \\
\text { финансовой политике. }\end{array}$ & $\begin{array}{l}\text { Построение probit-модели } \\
\text { для выявления факторов, } \\
\text { увеличивающих вероятность } \\
\text { выхода компании на IPO. } \\
\text { Оценка причин выхода на }\end{array}$ & $\begin{array}{l}\text { Основные мотивы на IPO - снижение доли долга в структуре } \\
\text { капитала, финансирование инвестиций, использование «окон } \\
\text { возможностей». После выхода на публичный рынок, стоимость } \\
\text { привлечения долга для компании снижается и одновременно } \\
\text { растет число банков-кредиторов. }\end{array}$ \\
\hline
\end{tabular}

Выпуск \#1, 2007

() Электронный журнал Корпоративные Финансы, 2007 


\begin{tabular}{|c|c|c|c|}
\hline & & $\begin{array}{l}\text { IPO ex post через анализ } \\
\text { изменения показателей } \\
\text { деятельности компании } \\
\text { после листинга. }\end{array}$ & $\begin{array}{l}\text { Часто компании выходят на IPО с целью дальнейшей продажи } \\
\text { компании. }\end{array}$ \\
\hline $\begin{array}{l}\text { Stewart Myers , } \\
2000\end{array}$ & $\begin{array}{l}\text { Вопросы финансирования } \\
\text { компании с точки зрения прав } \\
\text { собственности }\end{array}$ & $\begin{array}{l}\text { Две теоретические модели } \\
\text { взаимодействия внешних } \\
\text { инвесторов и инсайдеров - } \\
\text { модель партнерства и модель } \\
\text { корпорации. }\end{array}$ & $\begin{array}{l}\text { Выход на IPО обусловлен желанием предпринимателя сохранить } \\
\text { контроль над компанией, так как в случае частного } \\
\text { финансирования возникает угроза перехода прав собственности к } \\
\text { внешним крупным инвесторам. }\end{array}$ \\
\hline $\begin{array}{l}\text { Woojin Kim and } \\
\text { Michael Weisbach, } \\
2005\end{array}$ & $\begin{array}{l}\text { Исследование истинных } \\
\text { мотивов выхода на IPO, } \\
\text { сравнение компаний, } \\
\text { вышедших на IPO с первичной } \\
\text { продажей акций, и компаний, } \\
\text { где акционеры реализуют часть } \\
\text { собственных акций во время } \\
\text { ІРО. }\end{array}$ & $\begin{array}{l}\text { Строятся регрессионные } \\
\text { уравнения для выявления } \\
\text { зависимости показателей } \\
\text { компании после выхода на } \\
\text { IPO от структуры выпуска } \\
\text { компании. }\end{array}$ & $\begin{array}{l}\text { Мотивы выхода отражаются в структуре выпуска компании. } \\
\text { Первичная продажа акций связана с последующим ростом } \\
\text { инвестиций, ростом выплат по долгу, ростом наличности } \\
\text { компании. Привлечение нового капитала является важным } \\
\text { мотивом выхода компании с IPО. В случае размещения на IPO } \\
\text { акций первоначальных собственников стимулом выхода на IPO } \\
\text { служит желание собственников повысить ликвидность своей доли. }\end{array}$ \\
\hline $\begin{array}{l}\text { Simon Benninga, } \\
\text { Mark Helmantel } \\
\text { and Oded Sarig, } \\
2005\end{array}$ & $\begin{array}{l}\text { Оценка влияния издержек и } \\
\text { выгод от IPO на структуру } \\
\text { выпуска. }\end{array}$ & $\begin{array}{l}\text { Регрессионный анализ } \\
\text { методом МНК и } \\
\text { двухшаговым МНК. } \\
\text { Моделирование времени } \\
\text { выхода компании на IPO, где } \\
\text { выход на ІРО определяется } \\
\text { максимизацией стоимости } \\
\text { компании в каждый момент } \\
\text { времени с точки зрения } \\
\text { собственника. }\end{array}$ & $\begin{array}{l}\text { Подтверждается мотив вывода компании на IPO с целью } \\
\text { дальнейшей продажи компании. При этом вероятность смены } \\
\text { контроля меньше у фирм с высоким рычагом и с высокой } \\
\text { доходностью, и выше для компаний, выходящих на IPО только со } \\
\text { вторичными акциями. Для известных крупных компании самый } \\
\text { важный мотив - ликвидность и использование «окон } \\
\text { возможностей», ими предлагаются в основном только вторичные } \\
\text { акции. Владельцы компании выпускают акции в периоды больших } \\
\text { денежных потоков компании, которые совпадают с периодами } \\
\text { высоких цен на фондовом рынке. В периоды маленьких денежных }\end{array}$ \\
\hline
\end{tabular}

Выпуск \#1, 2007 


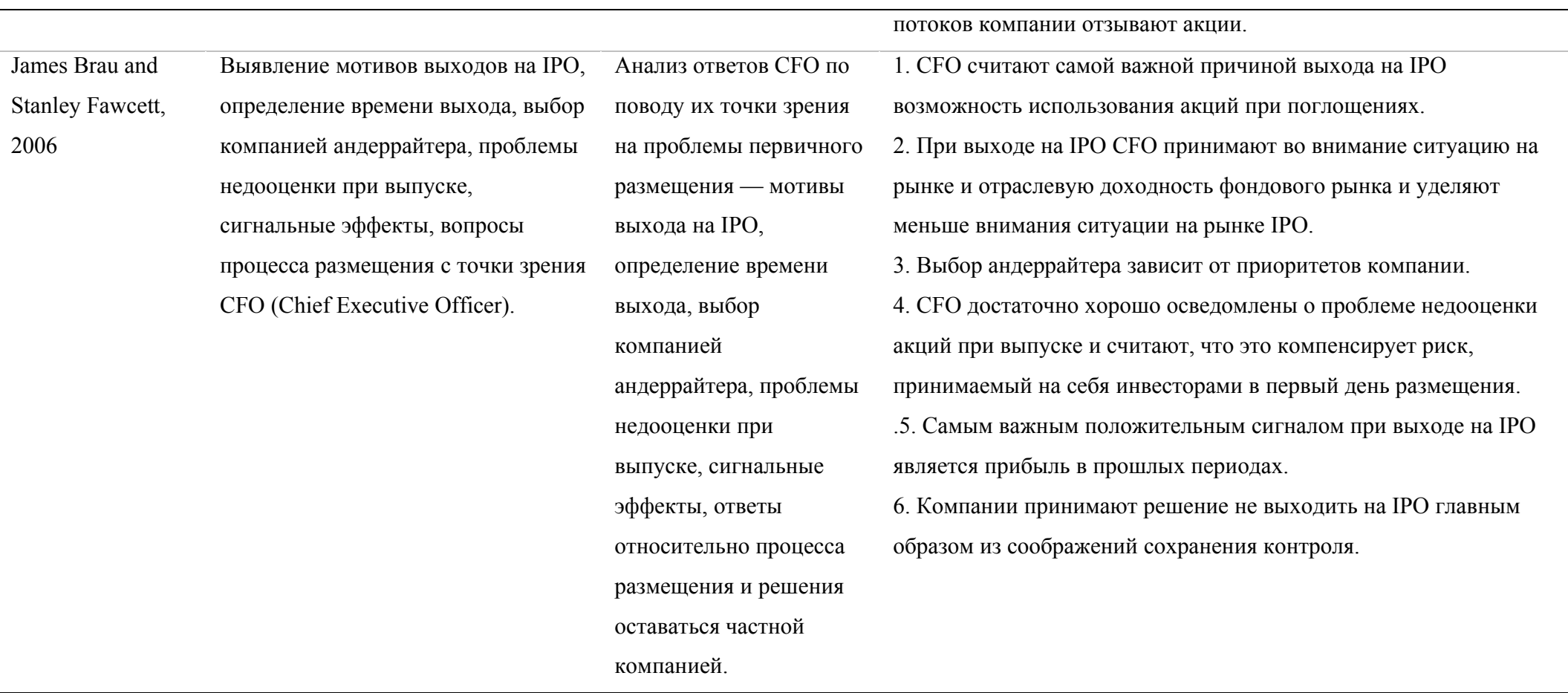




\section{Исследование IPО с точки зрения инвестиционного банка (андеррайтера)}

Процесс выхода на публичный рынок сопряжен с многими процедурами, в которых активное участие принимает инвестиционный банк (андеррайтер) в команде с аналитиками и брокерским подразделением. Процессы подготовки к началу торгов, ценообразование и поддержание рынка также дают почву для различных исследований, нацеленных на объяснение поведения и логики андеррайтера, рисков и всевозможных феноменов при выпуске.

Аггарвал и Конрой [Aggarwal \& Conroy, 2000] исследуют процесс ценообразования при начале торгов маркет-мэйкером, в результате чего выявляется взаимосвязь котировки, выставляемой в первые секунды пятиминутного интервала перед началом торгов, и последующего изменения цены. Также выявляется сильная зависимость доходности первого дня и времени дня начала торгов.

Авторы ссылаются на работы Шульц и Заман [Schultz \& Zaman, 1994] и Барри и Дженнингс [Barry \& Jennings, 1992], указывающих, что цена первой сделки объясняет большую часть доходности первого дня, и объясняют эмпирически изменение цены от изначальной цены предложения до цены первой сделки.

Данная проблема существует для андеррайтера, так как акция не торговалась в прошлом, при первичном размещении выявление истинной рыночной цены затруднено, поэтому возможны существенные колебания.

Для выявления истинной рыночной цены в процессе IPO чрезвычайно важен интервал времени, в который поступают необязательные заявки от маркет-мэйкеров. Авторы приходят к результату, что выпуски, по которым торги начинаются позже, имеют большую недооценку и цена первой сделки значительно определяет величину доходности первого дня.

Аггарвал [Aggarwal, 2000] исследует, как специальные стабилизирующие действия андеррайтеров влияют на поведение цены размещения акций во время IPO. В работе рассматривается, как происходит вмешательство андеррайтера во время размещения, в какой форме и в течение какого временного промежутка, каковы издержки такого вмешательства и как деятельность отражается на изменении цены акций.

Рассматривается три вида стабилизирующей деятельности андеррайтера во время размещения.

\section{«Чистая стабилизация»}

В случае неполного размещения акций андеррайтер покупает часть акций для того, чтобы поддержать предложение и повысить цену. Цена 
покупки не должна превышать цену размещения. Андеррайтер обязан указывать, что выкуп акций идет с целью стабилизации, следовательно, рынок получает сигнал о слабом спросе на данные акции и применение данной меры является нежелательной для андеррайтера.

\section{позищий \\ Покупка акций после размещения эмиссии для покрытия коротких}

Андеррайтер выкупает акции у компании перед размещением и реализует их в первый день выхода на IPO. При этом он имеет и реализует право покупки дополнительных 15\% эмиссии, которые он размещает на рынке в момент выхода на IPO. В дальнейшем он покупает на рынке избыток акций, тем самым стимулируя спрос. Процедура стабилизации не требует раскрытия действий андеррайтера для рынка.

Штрафы для предотвращения покупок акиий с иелью получения прибыли от их перепродажи сразу после размещения (flipping)

Андеррайтер может штрафовать членов продающей группы, лишая их комиссии, если их клиенты покупают акции при первичном размещении и продают их в течение последующих дней с целью получения прибыли. Мера используется для ограничения предложения и уменьшения спекулятивного давления на цену.

Андеррайтеры могут использовать все меры стабилизации и их комбинации. До размещения они могут устанавливать величину штрафов для продающих групп и выкупать избыточное количество акций для их продажи. После размещения андеррайтеры могут покупать на рынке те акции, которые продают участники торгов для получения спекулятивной прибыли в первые дни, и тем самым стабилизировать цену. При слабом спросе андеррайтер должен иметь достаточное количество коротких позиций по акциям, для того чтобы уменьшить давление от спекулятивных операций на рынке.

Для анализа используются данные по размещению 137 фирм. Информация об использовании стабилизационных мер была получена непосредственно от андеррайтеров.

Анализ описательных статистик данных показал, что андеррайтеры никогда не прибегают к «чистой стабилизации», что противоречит мнению Бенвенисте и пр. [Benveniste et al., 1996, 1998] о том, что «чистая стабилизация» распространена. Они предпочитают регулировать цену, покупая акции после первичного распределения акций. При этом достигнутые результаты не уступают методу «чистой стабилизации», но удается избежать раскрытия информации о действиях андеррайтера. Короткую позицию необходимо принимать до начала торгов, то есть покупать у компании акции сверх эмиссии. Исследование показывает, что покрытие этих коротких позиций происходит, даже если цена акций 
растет. Значит, андеррайтер не может точно предсказать, какие акции будут торговаться выше, а какие ниже цены размещения. При этом расходы андеррайтера на покрытие коротких позиций незначительны по сравнению с доходом, получаемым при размещении эмиссии. Штрафные санкции применяются исключительно в случаях слабого спроса на акции. Использование комбинации мер по стабилизации цены акций позволяет уменьшить издержки андеррайтера.

Авторы проверяют гипотезу, что существует прямая зависимость между деятельностью андеррайтера на рынке после размещения и доходностью акций. Для проверки гипотезы строится регрессия, где в качестве зависимой переменной берется доходность акции в течение 1, 20 и 40 дней. В качестве независимых переменных рассматриваются: цена размещения акций, выручка от размещения, дамми для штрафов, количество покрытых коротких позиций андеррайтера после размещения акций, выручка/потери от покрытия позиций, количество инвестиционных банков в синдикате. Результаты регрессии свидетельствуют о том, что необходимо учитывать деятельность андеррайтера при моделировании поведения цен акций при IPO. После окончания деятельности андеррайтера по стабилизации рынка наблюдается небольшое снижение цены, однако в течение нескольких дней цена поднимается до прежнего уровня.

Боувэр [Bower, 1989] рассматривает влияние метода выпуска акций на IPO на затраты фирмы при размещении и роль метода выпуска в сигнализировании инвесторам о качестве фирмы.

При выпуске акций на IPO компании андеррайтер может выкупить полностью весь выпуск и затем постепенно продавать на рынке, данный вид размещения гарантирует компании получение фиксированной суммы и размещение гарантированного количества акций по фиксированной цене («firm commitment basis»). C другой стороны, андеррайтер может предложить продавать как можно больше акций до определенного предела, не гарантируя полного размещения (при размещении меньше минимального барьера выпуск, как правило, будет отозван), но прикладывая все усилия для того, чтобы продать максимально возможное число акций в рамках изначального лимита (так называемый метод «bestefforts basis»).

Авторы считают и исследуют в своей работе, что выбор того или иного метода по-разному сказывается на затратах фирмы при размещении и передает инвесторам сигналы о качестве фирмы.

Авторы разрабатывают модель, в которой приводится частично объединяющее и частично разделяющее равновесия, при этом фирмы хорошего качества пытаются сигнализировать инвесторам через выбор полного выкупа (firm commitment) о своем качестве, а фирмы низкого качества выбирают метод максимальных усилий (best-efforts basis) и не могут отделить себя от других фирм. 
Основная идея работы заключается в построении модели, описывающей выбор фирмы вида размещения в зависимости от NPV проектов, которые желает профинансировать фирма. Компании более высокого качества с проектами высокого NPV, согласно логике автора, будут использовать метод полного выкупа андеррайтером, который в определенном смысле подтверждает оценку компании инвесторам и, таким образом, дает позитивный сигнал. Компании, у которых проекты имеют NPV, недостаточный для покрытия затрат на андеррайтера для подтверждения их оценки, будут находиться в частично разделяющем равновесии и выпускать акции по средней цене. При этом после размещения, по мере того как инвесторам будет доступно больше информации о компании с методом максимальных усилий, они могут с большей точностью определить ее справедливую оценку и переоценивают акции. В результате этого акции компаний, выбравших метод максимальных усилий, будут характеризоваться большей волатильностью доходностей после размещения и недооценка будет по ним выше, чем по акциям компаний, использующих метод полного выкупа. Акции компаний с методом полного выкупа оценены более точно, так как их оценка подтверждена андеррайтером, так как андеррайтер выкупает полностью выпуск - он уверен, что сможет в дальнейшем его перепродать на рынке. 
Таблица 4.

Основные исследования тематики IPO с точки зрения андеррайтера

\begin{tabular}{|c|c|c|c|}
\hline Авторы и год & Основные проблемы & Метод исследования & Основные результаты \\
\hline $\begin{array}{l}\text { Nancy L. Bower, } \\
1989\end{array}$ & $\begin{array}{l}\text { Выбор компанией метода } \\
\text { размещения акций на IPO (firm } \\
\text { commitment vs. best-efforts basis), } \\
\text { его влияние на затраты фирмы } \\
\text { при размещении и роль в } \\
\text { сигнализировании инвесторам о } \\
\text { качестве фирмы. }\end{array}$ & $\begin{array}{l}\text { Модель выбора компанией } \\
\text { метода размещения в } \\
\text { зависимости от качества } \\
\text { фирмы (наличия проектов с } \\
\text { различными NPV), затрат на } \\
\text { размещение и необходимых } \\
\text { инвестиций. }\end{array}$ & $\begin{array}{l}\text { Рассчитывается частично объединяющее и частично разделяющее } \\
\text { равновесие, где фирмы с лучшим качеством используют метод } \\
\text { полного выкупа для сигнализирования инвесторам о своем } \\
\text { качестве, а компании, имеющие NPV ниже барьерного уровня, не } \\
\text { покрывающего затрат на андеррайтера в случае полного выкупа, } \\
\text { используют метод максимальных усилий и оцениваются } \\
\text { инвесторами на среднем уровне. После начала торгов цена } \\
\text { последних компаний корректируется с поступлением новой } \\
\text { информации, соответственно волатильность будет выше, чем по } \\
\text { акциям, оцененным более точно андеррайтером при выпуске } \\
\text { методом полного выкупа. }\end{array}$ \\
\hline $\begin{array}{l}\text { Reena Aggarwal \& } \\
\text { Pat Conroy, } 2000\end{array}$ & $\begin{array}{l}\text { Проблема ценообразования на } \\
\text { акции IPO в первые минуты } \\
\text { торгов. }\end{array}$ & $\begin{array}{l}\text { Построение регрессии } \\
\text { отклонения цены открытия } \\
\text { от цены предложения на } \\
\text { отклонение первой } \\
\text { котировки от цены } \\
\text { предложения. Регрессия } \\
\text { доходности первого дня от } \\
\text { времени начала торгов. }\end{array}$ & $\begin{array}{l}\text { Первая выставленная андеррайтером котировка в значительной } \\
\text { степени предсказывает доходность первого дня. Время начала } \\
\text { торгов также значимо положительно влияет на доходность } \\
\text { первого дня. }\end{array}$ \\
\hline $\begin{array}{l}\text { Reena Aggarwal, } \\
2000\end{array}$ & $\begin{array}{l}\text { Влияние стабилизирующих } \\
\text { действий андеррайтера на } \\
\text { поведение цены размещения } \\
\text { акций. }\end{array}$ & $\begin{array}{l}\text { Анализ описательных } \\
\text { статистик для выявления } \\
\text { форм стабилизирующих } \\
\text { действий андеррайтера и их }\end{array}$ & $\begin{array}{l}\text { 1. Андеррайтеры никогда не прибегают к «чистой стабилизации». } \\
\text { 2. Регулирование цены происходит за счет покупки акции после } \\
\text { первичного распределения акций. При этом достигаются хорошие } \\
\text { результаты по стабилизации. }\end{array}$ \\
\hline
\end{tabular}

Выпуск \#1, 2007 
последствий. Регрессионный

анализ зависимости

доходности от: цены

размещения, выручки от

размещения, штрафов,

количества покрытых

коротких позиций

андеррайтера после

размещения, выручка/потери

от покрытия позиций,

количества инвестиционных

банков в синдикате.
3. Штрафные санкции применяются исключительно в случаях

слабого спроса на акции. Использование комбинации мер позволяет уменьшить издержки андеррайтера.

4. Необходимо учитывать деятельность андеррайтера при моделировании поведения цен акций при IРО. После окончания деятельности андеррайтера по стабилизации рынка наблюдается небольшое снижение цены, однако в течение нескольких дней цена поднимается до прежнего уровня. 


\section{Заключение}

В данной статье были рассмотрены наиболее популярные работы по тематике IPO. Даже краткий обзор показал, что выход компании на фондовый рынок сопровождается целым комплексом проблем. В работе приводится рассмотрение разнообразных проблем в рамках трех подходов к проблематике IPO - с точки зрения новых и изначальных акционеров, с точки зрения компании как независимой хозяйственной единицы в рамках бизнес-среды и с точки зрения инвестиционного банка и инфраструктуры финансового рынка.

С точки зрения инвесторов были выделены проблемы конфликта интересов, анализ причин выхода на IPO, асимметрия информации, недооценка при выпуске и пониженная доходность акций IPO на длительном горизонте. $\mathrm{C}$ точки зрения компании выделялись преимущества публичного размещения, оптимальное время выхода на IPO, проблемы влияния IPO на эффективность, рост, конкурентные преимущества, на сравнительную доходность компании. Наконец, с точки зрения инвестиционного банка важным является выбор методов и технологии выпуска, анализ факторов успешного выхода на IPO, определение структуры выпуска, проблема стабилизации рынка после начала торгов, влияние покрытия аналитиками департаментов исследований инвестиционных банков на результаты IPO, влияние репутации андеррайтера на IPO.

В заключении еще раз подчеркнем актуальность исследования в условиях развития фондового рынка и роста объемов IPO в России и других развивающихся странах. В связи с этим можно указать и перспективное направление дальнейших исследований, а именно анализ вышеперечисленных проблем в разрезе стран и регионов, сравнение IPO в различных странах с точки зрения их особенностей, а также исследование особенностей IPO на развивающихся рынках. Особенно интересным представляется исследование асимметрии информации при выпуске и метод ее устранения, распределение стоимости между старыми и новыми акционерами в различных системах корпоративного управления, структура собственности при выпуске.

\section{Список литературы}

\section{Исследования с точки зрения инвесторов}

1. Aggarwal Reena, Prabhala R Nagpurnanand \& Puri Manju. Institutional Allocation in Initial Public Offerings: Empirical Evidence. The Journal of Finance, Vol. LVII, № 3 (2002), pp. 1421-1442. 
2. Brav Alan \& Gompers A. Paul. Myth or reality? The long-run underperformance of Initial Public Offerings: Evidence from venture and nonventure capital-backed companies. The Journal of Finance, Vol. LII, № 5 (1997), pp. 1791-1821.

3. Carter Richard \& Manaster Steven. Initial Public Offering and Underwriter reputation. The Journal of Finance, Vol. XLV, № 4 (1990), pp. 1045-1067.

4. Carter B. Richard, Dark H. Frederick, and Singh K. Ajai. Underwriter reputation, initial returns, and the long-run performance of IPO stocks. The Journal of Finance, Vol LIII, № 1 (1998), pp. 285-311.

5. Cliff T. Michael \& Denis J. David. Do Initial Public Offering Firms Purchase Analyst Coverage with Underpricing? The Journal of Finance, Vol. LIX, № 6 (2004), pp. 2871-2901.

6. Field, Laura Casares. «Is institutional investment in Initial Public Offerings related to the long-run performance of these firms? Abstracts of papers presented at the 1996 AFA Meetings, pp. 1039-1040.

7. Gale Ian \& Stiglitz Joseph E.The Informational Content of Initial Public Offerings. The Journal of Finance, Vol. XLIV, № 2 (1989), pp. 469-477.

8. Gompers A. Paul \& Lerner Josh. The really Long-run Performance of Initial Public Offerings: The Pre-NASDAQ Evidence. The Journal of Finance, Vol. LVIII, № 4 (2003), pp. 1355-1392.

9. Loughran Tim \& Ritter R. Jay. The new issues puzzle. The Journal of Finance, Vol. L, № 1 (1995), pp. 23-51.

10. Megginson L. William \& Weiss A. Kathleen. Venture Capitalist Certification in Initial Public Offerings. The Journal of Finance, Vol. XLVI, № 3 (1991), pp. 879-903.

11. Rajan Raghuram \& Servaes Henri. Analyst Following of Initial Public Offerings. The Journal of Finance, Vol. LII, № 2 (1997), pp. 507-529.

12. Ritter Jay. Signaling and the Valuation of Unseasoned New Issues: A Comment. The Journal of Finance, Vol. XXXIX, № 4 (1984), pp. 12311237.

13. Ritter R. Jay. The Long-Run Performance of Initial Public Offerings. The Journal of Finance, Vol. XLVI, № 1 (1991), pp. 3-27.

\section{Исследования с точки зрения компании}

1. Arugaslan Onur, Cook O. Douglas, \& Kieschnick Robert. Monitoring as a Motivation for IPO Underpricing. The Journal of Finance, Vol. LIX, № 5 (2004), pp. 2403-2420.

2. Stewart Myers. Outside Equity. The Journal of Finance, Vol. 55, № 3. (2000), pp. 1005-1037.

3. Benninga Simon, Helmantel Mark, Sarig Oded. The timing of initial public offerings. Journal of Financial Economics, 75 (2005), pp. 115-132. 
4. Brau James \& Fawcett Stanley. Initial Public Offerings: An Analysis of Theory and Practice. The Journal Of Finance, Vol. LXI, № 1 (2006), pp. $399-436$.

5. Huyghebaert Nancy \& Van Hulle Cynthia Structuring the IPO: Empirical evidence on the portions of primary and secondary shares. Journal of Corporate Finance, 12 (2006), pp. 296 - 320.

6. Jain Bharat A. \& Kini Omesh. The Post-Issue Operating Performance of IPO Firms. The Journal of Finance, Vol. XLIX, № 5 (1994), pp. 16991726.

7. Kim Woojin \& Weisbach S. Michael. Do Firms Go Public To Raise Capital? NBER Working Paper № W11197 (2005).

8. Pagano Marco, Panetta Fabio, Zingales Luigi. Why Do Companies Go Public? An Empirical Analisys. Journal of Finance 53 (1998), pp. 27-64.

9. Pastor Lubos \& Veronesi Pietro. Rational IPO Waves. The Journal of Finance, Vol. LX, № 4 (2005), pp. 1713-1757.

\section{Исследования с точки зрения андеррайтера}

1. Aggarwal Reena \& Conroy Pat. Price discovery in Initial Public Offerings and the role of the lead underwriter. The Journal of Finance, Vol. LV, № 6 (2000), pp. 2903-2922.

2. Aggarwal Reena. Stabilization Activities by Underwriters after Initial Public Offering. The Journal of Finance, Vol. LV, № 3 (2000), pp. 1075-1103.

3. Bower L. Nancy. Firm Value and the Choice of Offering Method in Initial Public Offerings. The Journal of Finance, Vol. XLIV, № 3 (1989), pp. $647-662$. 